\title{
Chemical Synthesis, 17ß-Hydroxysteroid Dehydrogenase Type 1 Inhibitory Activity and Assessment of In Vitro and In Vivo Estrogenic Activities of Estradiol Derivatives
}

\author{
François Rouillard, Julie Lefebvre, Michelle-Audrey Fournier and Donald Poirier*
}

\author{
Medicinal Chemistry Division, Oncology and Molecular Endocrinology Laboratory, CHUQ-CHUL Research Center \\ and Université Laval, Québec (Québec), Canada
}

\begin{abstract}
HSD1) was chosen as a key steroidogenic target enzyme to reduce the formation of estradiol (E2), which is the most potent estrogen. This article completes a previous study by synthesizing and testing $16 \beta$-methylene derivatives $(\mathrm{Br}, \mathrm{Cl}$ and $\mathrm{OH})$ of $\mathrm{E} 2$ in order to generate new structure-activity relationships. This study also investigates a series of 2-methoxy $(\mathrm{MeO})$ derivatives synthesized as non-estrogenic inhibitors of $17 \beta-\mathrm{HSD} 1$. The 2-MeO- $\mathrm{E}_{2}$ derivatives $\left(16 \beta-\mathrm{CH}_{2} \mathrm{Br}, 16 \beta-\right.$ $\mathrm{CH}_{2} \mathrm{OH}$ and $\left.16 \alpha-\left(\mathrm{CH}_{2}\right)_{3} \mathrm{Br}\right)$ are all less potent inhibitors $\left(\mathrm{IC}_{50}=5.91,3.80\right.$ and $\left.5.80 \mu \mathrm{M}\right)$ than analogues without the 2- $\mathrm{MeO}$ group $\left(\mathrm{IC}_{50}=1.20,1.27\right.$ and $0.99 \mu \mathrm{M}$, respectively) for the reduction of estrone into $\mathrm{E} 2$ by $17 \beta$-HSD1 overexpressed in HEK-293 cells. Except for one compound, these E2 derivatives have shown an estrogenic-like effect on estrogen-sensitive T-47D cells at $1 \mu \mathrm{M}$. A cytotoxic effect was also obtained at higher concentrations for two compounds tested on T-47D cells. However, no estrogenic-like effect was observed in the estrogen-sensitive tissues (uterus and vagina) of the ovariectomized mouse model for 2-MeO$16 \alpha$-bromopropyl- $\mathrm{E}_{2}$.
\end{abstract}

Key Words: Steroid, Estradiol, Estrogen, Inhibitor, Hydroxysteroid dehydrogenase.

\section{INTRODUCTION}

17 $\beta$-hydroxysteroid dehydrogenases (17 $\beta$-HSDs) form an interesting enzyme family involved in the biosynthesis of sex steroids from cholesterol and targeted for controlling the concentration of estrogens and androgens [1-6]. From a therapeutic standpoint, inhibitors of $17 \beta-H S D s$ will no doubt be useful tools in the treatment of estrogen-sensitive pathologies (breast, ovarian and endometrium cancers) and androgeno-sensitive pathologies (prostate cancer, benign prostatic hyperplasia, hirsutism, etc.) [7-12]. Since 17ßHSDs exert their action at the end of the steroidogenesis of active steroidal hormones, selective inhibitors of these enzymes should not display undesired effects on the biosynthesis of other steroidal hormones such as aldosterone and cortisol. We are also aware that the activity of the $17 \beta$-HSDs in intact cells is mainly unidirectional [4, 13]. Each member of the 17ß-HSDs family can therefore be classified either as reductive or oxidative. $17 \beta$-HSD1 was the first known of this enzyme family and 3D structures of enzyme, complexed or not with substrate or/and cofactor have been elucidated [1417]. $17 \beta$-HSD1 catalyzes the reductive transformation of the less potent estrogen estrone (E1) into the most potent one, estradiol (E2). It also catalyzes the transformation of dehydroepiandrosterone (DHEA) into 5 -androstene-3 $\beta, 17 \beta$-diol

*Address correspondence to this author at the Medicinal Chemistry Division, Oncology and Molecular Endocrinology Laboratory, CHUQ-CHUL Research Center, T3-67, 2705 Laurier Boulevard Québec (Québec), G1V 4G2, Canada Ph.: 418654 2296; Fax: 418654 2761;

E-mail: donald.poirier@crchul.ulaval.ca
$\left(\Delta^{5}\right.$-diol), although at a lower rate (Fig. 1). Inhibition of this enzyme in a way that would decrease the level of E2 in the bloodstream as well as in peripheral tissues could be a good strategy in the fight against estrogen-sensitive diseases.

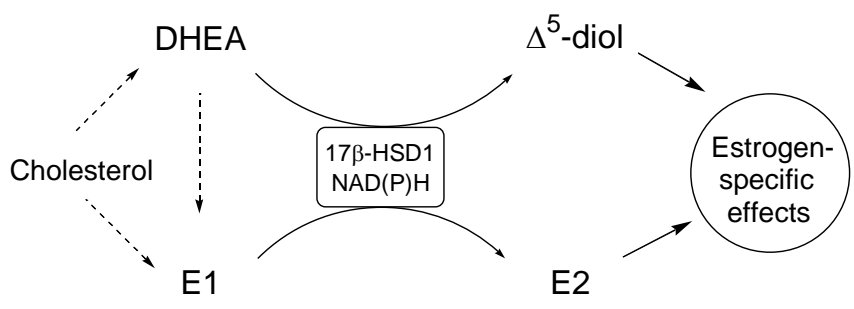

Fig. (1). Formation of weak estrogen $\Delta^{5}$-diol and potent estrogen E2 by $17 \beta-\mathrm{HSD} 1$ and cofactor $\mathrm{NAD}(\mathrm{P}) \mathrm{H}$.

In the late nineties, our research team performed a structure-activity relationship study for a series of $16 \alpha$ and $16 \beta-$ (bromoalkyl)-E2 inhibitors of 17ß-HSD1 [11]. The main conclusion was that $16 \alpha$-(bromopropyl)-E2 (5a) and $16 \beta$ (bromopropyl)-E2 (5b) are the two compounds that offered optimal inhibition of 17ß-HSD1 (Table 1). However, 5b is not fully stable and undergoes cyclization with loss of inhibitory activity. Although the inhibitory potency is slightly decreased for a 4-carbon side chain, (compounds $\mathbf{4 a}$ and $\mathbf{4 b}$ ) there is a drastic decrease of the inhibitory potency for $16 \alpha$ (bromoethyl)-E2 (6a), a 2-carbons side chain, but the result for the $16 \beta$ analogue was not obtained. In fact the synthesis of $16 \beta$-(bromoethyl)-E2 (6b) is not possible because of the formation of a highly stable 5-member ring ether. The synthesis of 163-(bromomethyl)-E2 (7) is however possible and 
will allow verification by extrapolation, if the inhibitory activity of the various $16 \beta$-(bromoalkyl)-E2 compounds follows the same tendency as observed for the $16 \alpha$ analogues. In the meantime, the synthesis of $16 \beta$-chloromethyl-E2 (8) and 16 $\beta$-hydroxymethyl-E2 (9) will make it possible to evaluate the influence of these two different atoms that, similarly to the $16 \beta$-bromomethyl group, closely proximate the tyrosine-155 of the catalytic triad and the nicotinamide nucleus of the cofactor $\mathrm{NAD}(\mathrm{P}) \mathrm{H}$, both components involved in the catalytic process.

Table 1. E2 Derivatives at Position 16 Previously Reported (1-6) or Newly Synthesized (7-12) as Inhibitors of 17ß-HSD1

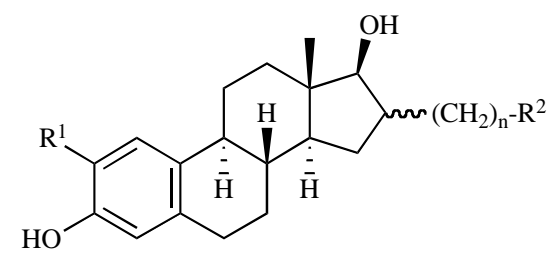

\begin{tabular}{|c|c|c|c|c|}
\hline$\#$ & $\mathbf{R}^{1}$ & $\mathbf{n}$ & $\begin{array}{c}\text { C16 } \\
(\alpha \text { or } \beta)\end{array}$ & $\mathbf{R}^{2}$ \\
\hline $1 \mathrm{a}$ & $\mathrm{H}$ & 7 & $\alpha$ & $\mathrm{Br}$ \\
\hline $1 b$ & $\mathrm{H}$ & 7 & $\beta$ & $\mathrm{Br}$ \\
\hline $2 a$ & $\mathrm{H}$ & 6 & $\alpha$ & $\mathrm{Br}$ \\
\hline $2 b$ & $\mathrm{H}$ & 6 & $\beta$ & $\mathrm{Br}$ \\
\hline $3 \mathbf{a}$ & $\mathrm{H}$ & 5 & $\alpha$ & $\mathrm{Br}$ \\
\hline $3 b$ & $\mathrm{H}$ & 5 & $\beta$ & $\mathrm{Br}$ \\
\hline $4 a$ & $\mathrm{H}$ & 4 & $\alpha$ & $\mathrm{Br}$ \\
\hline $4 b$ & $\mathrm{H}$ & 4 & $\beta$ & $\mathrm{Br}$ \\
\hline $5 a$ & $\mathrm{H}$ & 3 & $\alpha$ & $\mathrm{Br}$ \\
\hline $5 b$ & $\mathrm{H}$ & 3 & $\beta$ & $\mathrm{Br}$ \\
\hline $6 a$ & $\mathrm{H}$ & 2 & $\alpha$ & $\mathrm{Br}$ \\
\hline $6 b$ & $\mathrm{H}$ & 2 & $\beta$ & $\mathrm{Br}$ \\
\hline 7 & $\mathrm{H}$ & 1 & $\beta$ & $\mathrm{Br}$ \\
\hline 8 & $\mathrm{H}$ & 1 & $\beta$ & $\mathrm{Cl}$ \\
\hline 9 & $\mathrm{H}$ & 1 & $\beta$ & $\mathrm{OH}$ \\
\hline 10 & $\mathrm{CH}_{3} \mathrm{O}$ & 1 & $\beta$ & $\mathrm{Br}$ \\
\hline 11 & $\mathrm{CH}_{3} \mathrm{O}$ & 1 & $\beta$ & $\mathrm{OH}$ \\
\hline 12 & $\mathrm{CH}_{3} \mathrm{O}$ & 3 & $\alpha$ & $\mathrm{Br}$ \\
\hline
\end{tabular}

The first part of our work consists in completing the previous study performed by Tremblay et al. $[18,11]$ on $16 \alpha / \beta$ (bromoalkyl)-E2 as inhibitors of $17 \beta$-HSD1 by synthesizing compounds 7-9 (Table 1). Based on the fact that 2-methoxy (MeO)-E2 interacts negligibly with the estrogen receptor [19], we also performed the synthesis of 2-MeO-E2 derivatives 10-12, including the $2-\mathrm{MeO}$ version of the inhibitor 5a already synthesized by Tremblay and Poirier [18] but having residual estrogenic activity when tested on the estrogensensitive cell line ZR-75-1 [11]. This manuscript describes the chemical synthesis and biological evaluation of targeted compounds 7-12 as inhibitors of $17 \beta$-HSD1 with a special focus in addressing their in vitro and in vivo estrogenic effects.

\section{MATERIALS AND METHODOLOGY}

\section{Chemical Synthesis}

The starting steroid estrone was purchased from Steraloids Inc. (Newport, RI, USA). 2-Methoxy-estrone was synthesized from estrone similarly as reported in literature [20]. Chemical reagents of highest purity and anhydrous solvents were obtained from Sigma-Aldrich Canada Ltd. (Oakville, ON, Canada) and Fisher Scientific (Montréal, QC, Canada). Tetrahydrofuran used in the anhydrous reactions was distilled from benzophenone ketyl. Reactions were run under inert (argon) atmosphere in oven-dried glassware. Analytical thin-layer chromatography (TLC) was performed on $0.20 \mathrm{~mm}$ silica gel 60 F254 plates (Fisher Scientific), and compounds were visualized using UV light or ammonium molybdate/sulfuric acid/water (with heating). Flash column chromatographies were performed upon Silicycle R10030B 230-400 mesh silica gel (Québec, QC, Canada). Infrared spectra (IR) were obtained from a thin film of compound usually solubilized in $\mathrm{CDCl}_{3}$ and deposited upon an $\mathrm{NaCl}$ pellet. They were recorded with a Perkin-Elmer 1600 FT-IR spectrometer (Norwalk, CT, USA) and only the significant bands were reported in $\mathrm{cm}^{-1}$. Nuclear magnetic resonance (NMR) spectra were recorded at $300 \mathrm{MHz}\left({ }^{1} \mathrm{H}\right)$ and 75.5 $\mathrm{MHz}\left({ }^{13} \mathrm{C}\right)$ on a Bruker AC/F300 spectrometer (Billerica, MA, USA) or a $400 \mathrm{MHz}\left({ }^{1} \mathrm{H}\right)$ and $100.6 \mathrm{MHz}\left({ }^{13} \mathrm{C}\right)$ on a Bruker Avance 400 digital spectrometer and reported in ppm. Low-resolution mass spectra (LRMS) were recorded on a PE Sciex API-150 ex apparatus (Foster City, CA, USA).

Synthesis of 3-tert-butyldimethylsilyloxy-estra-1,3,5(10)trien-17-one (13):

Estrone was protected as a $t$-butyldimethylsilyl ether as previously reported in literature [21].

\section{Synthesis of 2-methoxy-3-tert-butyldimethylsilyloxy-estra- 1,3,5(10)-trien-17-one (14):}

To a solution of 2-methoxy-estrone (1.12 g, $3.73 \mathrm{mmol})$ in dry $\mathrm{CH}_{2} \mathrm{Cl}_{2}(10 \mathrm{~mL})$ cooled at $0{ }^{\circ} \mathrm{C}$ were added dry triethylamine $(1.56 \mathrm{~mL}, 11.18 \mathrm{mmol})$ and $t$-butyldimethylsilyl chloride (TBDMS-Cl) (1.69 g, $11.18 \mathrm{mmol})$. The mixture was stirred under argon atmosphere from $0{ }^{\circ} \mathrm{C}$ to room temperature overnight. The reaction was then quenched with $\mathrm{MeOH}$, water added in excess, and the mixture extracted with $\mathrm{CH}_{2} \mathrm{Cl}_{2}$. The organic phase was washed several times with water, dried over $\mathrm{Na}_{2} \mathrm{SO}_{4}$ and evaporated under reduced pressure. The crude product was purified by flash chromatography, using a mixture of hexanes and EtOAc (9/1) as eluent to give 14 in a $76 \%$ yield. White solid; ${ }^{1} \mathrm{H}$ NMR 300 $\mathrm{MHz} \delta\left(\mathrm{CDCl}_{3}\right): 0.15\left(\mathrm{~s}, 6 \mathrm{H}, \mathrm{Si}\left(\mathrm{CH}_{3}\right)_{2}\right), 0.91$ (s, 3H, 18$\mathrm{CH}_{3}$ ), 0.99 (s, 9H, $t$-Bu of TBDMS), 1.20-2.60 (residual protons from the steroid), $2.77\left(\mathrm{~m}, 2 \mathrm{H}, 6-\mathrm{CH}_{2}\right), 3.75(\mathrm{~s}, 3 \mathrm{H}$, $\left.\mathrm{CH}_{3} \mathrm{O}\right), 6.55$ (s, 1H, 4-CH), 6.75 (s, 1H, 1-CH); ${ }^{13} \mathrm{C}$ NMR $75.5 \mathrm{MHz} \delta\left(\mathrm{CDCl}_{3}\right):-4.74(2 \mathrm{X}), 13.72,18.25,21.39,25.60$ (3X), 25.89, 26.48, 28.54, 31.43, 35.69, 38.05, 44.12, 47.82, 
$50.19, \quad 55.52, \quad 109.43, \quad 120.83, \quad 128.48, \quad 132.34,142.79$, 148.57, 220.78; LRMS calculated for $\mathrm{C}_{25} \mathrm{H}_{38} \mathrm{O}_{3} \mathrm{Si}$ : 414.2, found $415.0[\mathrm{M}+\mathrm{H}]^{+}$.

Synthesis of methyl-1-[3'-tert-butyldimethylsilyloxy-17'oxo-estra-1',3',5'(10')-trien-16' $\beta$-yl]-formate (15):

A solution of diisopropylamine $(1.00 \mathrm{~mL}, 7.14 \mathrm{mmol})$ in dry THF $(15 \mathrm{~mL})$ was stirred under argon at $-25{ }^{\circ} \mathrm{C}$ and a solution of $n$-butyllithium in hexanes $(2.88 \mathrm{~mL}, 7.20 \mathrm{mmol})$ was added dropwise. After 45 minutes, the resulting lithium diisopropylamide (LDA) solution was cooled at $-78{ }^{\circ} \mathrm{C}$ and TBDMS-E1 (13) $(2.2 \mathrm{~g}, 5.71 \mathrm{mmol})$ dissolved in dry THF $(15 \mathrm{~mL})$ was added dropwise. The mixture was allowed to stir for 1 hour at $0{ }^{\circ} \mathrm{C}$, then cooled again to $-78{ }^{\circ} \mathrm{C}$ and hexamethylphosphoramide (HMPA) $(1.00 \mathrm{~mL}, 5.71 \mathrm{mmol})$ was slowly added followed by methylcyanoformate $(0.46 \mathrm{~mL}$, $5.80 \mathrm{mmol}$ ). The reaction mixture was allowed to stir at -78 ${ }^{\circ} \mathrm{C}$ for 30 minutes before the reaction was fully completed. Water was added to quench the reaction and the crude product was extracted with EtOAc. The organic phase was washed with water and dried over $\mathrm{Na}_{2} \mathrm{SO}_{4}$. After evaporation under reduced pressure, the crude product was purified by flash chromatography, using a mixture of hexanes and EtOAc $(9 / 1)$ as eluent to give 15. Although a mixture of two C16 isomers ( $\beta$-major and $\alpha$-minor) was obtained in a $78 \%$ yield, only the major compound was recovered after chromatography. White solid; IR $v$ (film): 1752 and 1725 (C=O of ketone and ester); ${ }^{1} \mathrm{H}$ NMR $400 \mathrm{MHz} \delta\left(\mathrm{CDCl}_{3}\right): 0.21(\mathrm{~s}, 6 \mathrm{H}$, $\left.\mathrm{Si}\left(\mathrm{CH}_{3}\right)_{2}\right), 1.00$ (s, 9H, $t$-Bu of TBDMS), 1.01 (s, 3H, 18'$\mathrm{CH}_{3}$ ), 1.40-2.50 (residual protons from the steroid), 2.88 (m, $\left.2 \mathrm{H}, 6^{\prime}-\mathrm{CH}_{2}\right), 3.23$ (dd, $\mathrm{J}_{1}=8.5 \mathrm{~Hz}$ and $\mathrm{J}_{2}=9.8 \mathrm{~Hz}, 16^{\prime}-\mathrm{CH}$ ), $3.79\left(\mathrm{~s}, 3 \mathrm{H}, \mathrm{COOCH}_{3}\right), 6.60\left(\mathrm{~d}, \mathrm{~J}=2.5 \mathrm{~Hz}, 1 \mathrm{H}, 4^{\prime}-\mathrm{CH}\right), 6.65$ $\left(\mathrm{dd}, \mathrm{J}_{1}=8.4 \mathrm{~Hz}\right.$ and $\left.\mathrm{J}_{2}=2.6 \mathrm{~Hz}, 1 \mathrm{H}, 2^{\prime}-\mathrm{CH}\right), 7.13(\mathrm{~d}, \mathrm{~J}=8.4$ $\mathrm{Hz}, 1 \mathrm{H}, 1$ '-CH $) ;{ }^{13} \mathrm{C}$ NMR $75.5 \mathrm{MHz} \delta\left(\mathrm{CDCl}_{3}\right):-4.40(2 \mathrm{X})$, $13.27,18.15,25.67$ (3X), 26.33, 26.53, 29.36, 31.90, 37.84, $43.97,47.89,48.92,52.58,54.04,117.34,119.99,126.09$, $132.09,137.47,153.52,169.85,212.12$; LRMS calculated for $\mathrm{C}_{26} \mathrm{H}_{38} \mathrm{O}_{4} \mathrm{Si}$ : 442.3 , found $443.1[\mathrm{M}+\mathrm{H}]^{+}$.

Synthesis of methyl-1-[2'-methoxy-3'-tert-butyldimethyl silyloxy-17'-oxo-estra-1',3',5'(10')-trien-16' $\beta$-yll-formate (16):

Using the same protocol as for the synthesis of $\mathbf{1 5}$, the ester moiety was introduced upon $\mathbf{1 4}$ to give $\mathbf{1 6}$ in a $71 \%$ yield. Only the major 16 ' $\beta$-isomer was described. White solid; IR v (film): 1752 and $1728(\mathrm{C}=\mathrm{O}$ of ketone and ester); ${ }^{1} \mathrm{H}$ NMR $400 \mathrm{MHz} \delta\left(\mathrm{CDCl}_{3}\right): 0.17\left(\mathrm{~s}, 6 \mathrm{H}, \mathrm{Si}\left(\mathrm{CH}_{3}\right)_{2}\right), 1.01$ (s, 9H, $t$-Bu of TBDMS), 1.02 (s, 3H, $\left.18^{\prime}-\mathrm{CH}_{3}\right), 1.40-2.30$ (residual protons from the steroid), $2.80\left(\mathrm{~m}, 2 \mathrm{H}, 6^{\prime}-\mathrm{CH}_{2}\right)$, $3.24\left(\mathrm{dd}, 1 \mathrm{H}, \mathrm{J}_{1}=8.5 \mathrm{~Hz}\right.$ and $\left.\mathrm{J}_{2}=9.3 \mathrm{~Hz}, 16^{\prime} \alpha-\mathrm{CH}\right), 3.78(\mathrm{~s}$, $\left.3 \mathrm{H}, \mathrm{COOCH}_{3}\right), 3.79\left(\mathrm{~s}, 3 \mathrm{H}, 2{ }^{\prime}-\mathrm{CH}_{3} \mathrm{O}\right), 6.59(\mathrm{~s}, 1 \mathrm{H}, 1$ ' $-\mathrm{CH})$, $6.77\left(\mathrm{~s}, 1 \mathrm{H}, 4{ }^{\prime}-\mathrm{CH}\right) ;{ }^{13} \mathrm{C}$ NMR $75.5 \mathrm{MHz} \delta\left(\mathrm{CDCl}_{3}\right)$ : -4.59 (2X), 13.33, 18.43, 25.74 (3X), 25.93, 26.37, 26.67, 28.63, $31.96,37.84,38.30,44.31,47.92,52.61,54.08,55.82$, 109.72 , 121.05, 128.63, 132.21, 143.15, 148.83, 169.88, 212.18; LRMS calculated for $\mathrm{C}_{27} \mathrm{H}_{40} \mathrm{O}_{5} \mathrm{Si}$ : 472.5 , found $471.6[\mathrm{M}-\mathrm{H}]^{-}$and $495.3[\mathrm{M}+\mathrm{Na}]^{+}$.

Synthesis of 3-tert-butyldimethylsilyloxy-16ק-hydroxymeth$y$ l-estra-1,3,5(10)-trien-17 $\beta$-ol (17):

To a stirred solution of $15(0.830 \mathrm{~g}, 1.88 \mathrm{mmol})$ in dry THF $(15 \mathrm{~mL})$ at $-78{ }^{\circ} \mathrm{C}$ under argon atmosphere a solution of $\mathrm{LiAlH}_{4}$ in THF (3.4 mL, $\left.3.40 \mathrm{mmol}\right)$ was added dropwise. After 1 hour, the reaction mixture was warmed up to $0{ }^{\circ} \mathrm{C}$ and allowed to react for 30 minutes before it was fully completed. Water was added to quench the reaction and the crude product was extracted using EtOAc. The organic phase was washed with a saturated $\mathrm{NaCl}$ aqueous solution and dried over $\mathrm{Na}_{2} \mathrm{SO}_{4}$. After evaporation under reduced pressure, the crude product was purified by flash chromatography, using a mixture of hexanes and EtOAc (8/2) as eluent to give $\mathbf{1 7}$ in an $83 \%$ yield. White solid; IR $v$ (film): $3312(\mathrm{OH}) ;{ }^{1} \mathrm{H}$ NMR $400 \mathrm{MHz} \delta\left(\mathrm{CDCl}_{3}\right): 0.21$ (s, 6H, $\left.\mathrm{Si}\left(\mathrm{CH}_{3}\right)_{2}\right), 0.87$ (s, 3H, 18$\mathrm{CH}_{3}$ ), 1.00 (s, 9H, $t$-Bu of TBDMS), 1.05-2.40 (residual protons for the steroid), $2.50(\mathrm{~m}, 1 \mathrm{H}, 16 \alpha-\mathrm{CH}), 2.82(\mathrm{~m}, 2 \mathrm{H}, 6-$ $\left.\mathrm{CH}_{2}\right), 3.64\left(\mathrm{~m}, 1 \mathrm{H}\right.$ of $\left.\mathrm{CH}_{2} \mathrm{OH}\right), 3.87\left(\mathrm{~m}, 1 \mathrm{H}\right.$ of $\left.\mathrm{CH}_{2} \mathrm{OH}\right)$, $3.98(\mathrm{~d}, \mathrm{~J}=9.8 \mathrm{~Hz}, 1 \mathrm{H}, 17 \alpha-\mathrm{CH}), 6.58(\mathrm{~d}, \mathrm{~J}=2.5 \mathrm{~Hz}, 1 \mathrm{H}, 4-$ $\mathrm{CH}), 6.64\left(\mathrm{dd}, \mathrm{J}_{1}=8 \mathrm{~Hz}\right.$ and $\left.\mathrm{J}_{2}=2.5 \mathrm{~Hz}, 1 \mathrm{H}, 2-\mathrm{CH}\right), 7.14(\mathrm{~d}$, $\mathrm{J}=8 \mathrm{~Hz}, 1-\mathrm{CH}) ;{ }^{13} \mathrm{C}$ NMR $75.5 \mathrm{MHz} \delta\left(\mathrm{CDCl}_{3}\right):-4.40(2 \mathrm{X})$, $12.27,18.15,25.68$ (3X), 26.17, 27.47, 27.78, 29.56, 37.62, $38.05,41.81,43.84,44.24,49.06,64.77,83.03,117.15$, 119.92, 126.06, 132.90, 137.72, 153.27; LRMS calculated for $\mathrm{C}_{25} \mathrm{H}_{40} \mathrm{O}_{3} \mathrm{Si}: 416.3$, found $417.1[\mathrm{M}+\mathrm{H}]^{+}$.

Synthesis of 2-methoxy-3-tert-butyldimethylsilyloxy-16קhydroxymethyl-estra-1,3,5(10)-trien-17ß-ol (18):

Using the same protocol as for the synthesis of $\mathbf{1 7}$, the keto ester $\mathbf{1 6}$ was reduced to give compound $\mathbf{1 8}$ in a $76 \%$ yield. White solid; ${ }^{1} \mathrm{H}$ NMR $400 \mathrm{MHz} \delta\left(\mathrm{CDCl}_{3}\right): 0.17$ (s, $\left.6 \mathrm{H}, \mathrm{Si}\left(\mathrm{CH}_{3}\right)_{2}\right), 0.88\left(\mathrm{~s}, 3 \mathrm{H}, 18-\mathrm{CH}_{3}\right), 1.01(\mathrm{~s}, 9 \mathrm{H}, t-\mathrm{Bu}$ of TBDMS), 1.05-2.40 (residual protons from the steroid), 2.50 $(\mathrm{m}, 1 \mathrm{H}, 16 \alpha-\mathrm{CH}), 2.74\left(\mathrm{~m}, 2 \mathrm{H}, 6-\mathrm{CH}_{2}\right), 3.69(\mathrm{~m}, 1 \mathrm{H}$ of $\left.\mathrm{CH}_{2} \mathrm{OH}\right), 3.79\left(\mathrm{~s}, 3 \mathrm{H}, \mathrm{CH}_{3} \mathrm{O}\right), 3.87\left(\mathrm{~m}, 1 \mathrm{H}\right.$ of $\left.\mathrm{CH}_{2} \mathrm{OH}\right), 3.98$ $(\mathrm{d}, \mathrm{J}=9.8 \mathrm{~Hz}, 1 \mathrm{H}, 17 \alpha-\mathrm{CH}), 6.56(\mathrm{~s}, 1 \mathrm{H}, 4-\mathrm{CH}), 6.78(\mathrm{~s}, 1 \mathrm{H}$, $1-\mathrm{CH}) ;{ }^{13} \mathrm{C}$ NMR $75.5 \mathrm{MHz} \delta\left(\mathrm{CDCl}_{3}\right):-4.61(2 \mathrm{X}), 12.27$, $18.40,25.73$ (3X), 26.37, 27.57, 27.76, 28.78, 37.68, 37.99, $41.91,44.15,44.26,49.07,55.82,64.75,83.04,109.80$, $120.88,128.88,132.99,142.89,148.64$.

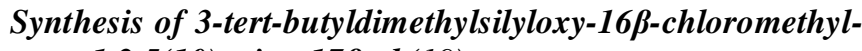
estra-1,3,5(10)-trien-17ß-ol (19):

A solution of diol $17(0.494 \mathrm{~g}, 1.196 \mathrm{mmol}), \mathrm{PPh}_{3}(0.627$ $\mathrm{g}, 2.392 \mathrm{mmol})$ and $\mathrm{CCl}_{4}(0.793 \mathrm{~g}, 2.392 \mathrm{mmol})$ in dry $\mathrm{CH}_{2} \mathrm{Cl}_{2}(20 \mathrm{~mL})$ was stirred at $0{ }^{\circ} \mathrm{C}$ under argon. The reaction was monitored by TLC and was completed after 3 hours. The crude mixture was pre-adsorbed on silica gel and purified by flash chromatography using a mixture of hexanes and EtOAc (95/5) as eluent to give $\mathbf{1 9}$ in a $60 \%$ yield. White solid; IR v (film): $3575(\mathrm{OH}) ;{ }^{1} \mathrm{H}$ NMR $400 \mathrm{MHz} \delta\left(\mathrm{CDCl}_{3}\right)$ : $0.20\left(\mathrm{~s}, 6 \mathrm{H}, \mathrm{Si}\left(\mathrm{CH}_{3}\right)_{2}\right), 0.84$ (s, $\left.3 \mathrm{H}, 18-\mathrm{CH}_{3}\right), 1.00$ (s, 9H, $t$ $\mathrm{Bu}$ of TBDMS), 1.10-2.40 (residual protons from the steroid), $2.59(\mathrm{~m}, 1 \mathrm{H}, 16 \alpha-\mathrm{CH}), 2.83\left(\mathrm{~m}, 2 \mathrm{H}, 6-\mathrm{CH}_{2}\right), 3.54$ (dd, $\mathrm{J}_{1}=8.4 \mathrm{~Hz}$ and $\mathrm{J}_{2}=10.7 \mathrm{~Hz}, 1 \mathrm{H}$ of $\left.\mathrm{CH}_{2} \mathrm{Cl}\right), 3.88\left(\mathrm{dd}, \mathrm{J}_{1}=\right.$ $6.8 \mathrm{~Hz}$ and $\mathrm{J}_{2}=10.8 \mathrm{~Hz}, 1 \mathrm{H}$ of $\left.\mathrm{CH}_{2} \mathrm{Cl}\right), 3.91(\mathrm{~d}, \mathrm{~J}=9.8 \mathrm{~Hz}$, $1 \mathrm{H}, 17 \alpha-\mathrm{CH}), 6.58(\mathrm{~d}, \mathrm{~J}=2.5 \mathrm{~Hz}, 1 \mathrm{H}, 4-\mathrm{CH}), 6.64\left(\mathrm{dd}, \mathrm{J}_{1}=8\right.$ $\mathrm{Hz}$ and $\left.\mathrm{J}_{2}=2.5 \mathrm{~Hz}, 1 \mathrm{H}, 2-\mathrm{CH}\right), 7.14(\mathrm{~d}, \mathrm{~J}=8 \mathrm{~Hz}, 1 \mathrm{H}, 1-\mathrm{CH})$; ${ }^{13} \mathrm{C}$ NMR $75.5 \mathrm{MHz} \delta\left(\mathrm{CDCl}_{3}\right):-4.40(2 \mathrm{X}), 12.27,18.15$, 25.68 (3X), 26.17, 27.47, 27.78, 29.56, 37.62, 38.05, 41.81, $43.84,44.24,49.06,64.77,83.03,117.15,119.92,126.06$, 132.90, 137.72, 153.27; LRMS calculated for $\mathrm{C}_{25} \mathrm{H}_{39} \mathrm{ClO}_{2} \mathrm{Si}$ : 434.5, found 479.5 for $\mathrm{C}_{26} \mathrm{H}_{40} \mathrm{ClO}_{4} \mathrm{Si}[\mathrm{M}+\mathrm{COOH}]$. 
Synthesis of 3-tert-butyldimethylsilyloxy-16ק-bromomethylestra-1,3,5(10)-trien-17ß-ol (20):

A solution of diol $17(0.519 \mathrm{~g}, 1.246 \mathrm{mmol}), \mathrm{PPh}_{3}(0.653$ $\mathrm{g}, 2.491 \mathrm{mmol})$ and $\mathrm{CBr}_{4}(0.826 \mathrm{~g}, 2.491 \mathrm{mmol})$ in dry $\mathrm{CH}_{2} \mathrm{Cl}_{2}(20 \mathrm{~mL})$ was stirred at $0{ }^{\circ} \mathrm{C}$ under argon. The reaction was monitored by TLC and was completed after 3 hours. The crude mixture was pre-adsorbed on silica gel and purified by flash chromatography using a mixture of hexanes and EtOAc (95/5) as eluent to give $\mathbf{2 0}$ in a $64 \%$ yield. White solid; IR v (film): $3560(\mathrm{OH}) ;{ }^{\mathrm{H}} \mathrm{NMR} 400 \mathrm{MHz} \delta\left(\mathrm{CDCl}_{3}\right)$ : 0.21 (s, $\left.6 \mathrm{H}, \mathrm{Si}\left(\mathrm{CH}_{3}\right)_{2}\right), 0.84$ (s, $\left.3 \mathrm{H}, 18-\mathrm{CH}_{3}\right), 1.00$ (s, $9 \mathrm{H}, t$ $\mathrm{Bu}$ of TBDMS), 1.10-2.35 (residual protons from the steroid), 2.65 (m, 1H, 16 $\alpha-\mathrm{CH}), 2.83$ (m, 2H, 6- $\left.\mathrm{CH}_{2}\right), 3.38$ (t, J = $9.5 \mathrm{~Hz}, 1 \mathrm{H}$ of $17 \alpha-\mathrm{CH}), 3.77\left(\mathrm{dd}, \mathrm{J}_{1}=9.8 \mathrm{~Hz}\right.$ and $\mathrm{J}_{2}=6.5 \mathrm{~Hz}$, $1 \mathrm{H}$ of $\left.\mathrm{CH}_{2} \mathrm{Br}\right), 3.88\left(\mathrm{dd}, \mathrm{J}_{1}=9.8 \mathrm{~Hz}\right.$ and $\mathrm{J}_{2}=6.5 \mathrm{~Hz}, 1 \mathrm{H}$ of $\left.\mathrm{CH}_{2} \mathrm{Br}\right), 6.58\left(\mathrm{~d}, \mathrm{~J}_{2}=2.4 \mathrm{~Hz}, 1 \mathrm{H}, 4-\mathrm{CH}\right), 6.64\left(\mathrm{dd}, \mathrm{J}_{1}=8.4\right.$ $\mathrm{Hz}$ and $\left.\mathrm{J}_{2}=2.4 \mathrm{~Hz}, 1 \mathrm{H}, 2-\mathrm{CH}\right), 7.14\left(\mathrm{~d}, \mathrm{~J}_{1}=8.4 \mathrm{~Hz}, 1 \mathrm{H}, 1-\right.$ $\mathrm{CH}) ;{ }^{13} \mathrm{C}$ NMR $75.5 \mathrm{MHz} \delta\left(\mathrm{CDCl}_{3}\right):-4.41(2 \mathrm{X}), 12.33$, $18.15,25.68$ (3X), 26.11, 27.41, 29.53, 31.21, 32.62, 36.53, $37.94,43.21,43.90,44.43,48.15,81.92,117.16,119.93$, $126.05,132.79,137.70,153.33$; LRMS calculated for $\mathrm{C}_{25} \mathrm{H}_{39}{ }^{81} \mathrm{BrO}_{2} \mathrm{Si}: 480.2$, found $481.1[\mathrm{M}+\mathrm{H}]^{+}$.

Synthesis of 21:

Using the same protocol as for the synthesis of $\mathbf{2 0}$, the bromination was performed upon diol 18. After extraction, the crude compound 21 was used without purification for the next step (TBDMS hydrolysis).

Synthesis of final compounds 7-11 (hydrolysis of silylated ethers 17-21):

Each of the silylated ethers 17-21 was dissolved in a methanolic solution of $\mathrm{HCl}(2 \% \mathrm{v} / \mathrm{v})$ and the resulting mixture was stirred at room temperature for 3 hours. Water was added, the $\mathrm{MeOH}$ evaporated under reduced pressure and the residue extracted with EtOAc. The organic phase was washed with a saturated $\mathrm{NaCl}$ aqueous solution and dried over $\mathrm{Na}_{2} \mathrm{SO}_{4}$. After evaporation under reduced pressure, the crude product was purified by flash chromatography, using a mixture of hexanes and EtOAc (8/2) as eluent to give the following final compounds in $85 \%$ to $95 \%$ yields

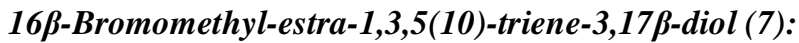

White solid; IR v (film): $3357(\mathrm{OH}) ;{ }^{1} \mathrm{H}$ NMR $300 \mathrm{MHz}$ $\delta\left(\mathrm{CDCl}_{3}\right): 0.81\left(\mathrm{~s}, 3 \mathrm{H}, 18-\mathrm{CH}_{3}\right), 1.10-2.35$ (residual protons from the steroid), $2.65(\mathrm{~m}, 1 \mathrm{H}, 16 \alpha-\mathrm{CH}), 2.79(\mathrm{~m}, 2 \mathrm{H}, 6-$ $\left.\mathrm{CH}_{2}\right), 3.36\left(\mathrm{t}, \mathrm{J}=9.5 \mathrm{~Hz}, 1 \mathrm{H}\right.$ of $\left.\mathrm{CH}_{2} \mathrm{Br}\right), 3.74\left(\mathrm{dd}, \mathrm{J}_{1}=6.5 \mathrm{~Hz}\right.$ and $\mathrm{J}_{2}=9.6 \mathrm{~Hz}, 1 \mathrm{H}$ of $\left.\mathrm{CH}_{2} \mathrm{Br}\right), 3.87(\mathrm{~d}, \mathrm{~J}=9.8 \mathrm{~Hz}, 1 \mathrm{H}, 17 \alpha-$ $\mathrm{CH}), 4.80$ (broad, OH), 6.57 (d, J = 2.7 Hz, 1H, 4-CH), 6.63 $\left(\mathrm{dd}, \mathrm{J}_{1}=2.7 \mathrm{~Hz}\right.$ and $\left.\mathrm{J}_{2}=8.4 \mathrm{~Hz}, 1 \mathrm{H}, 2-\mathrm{CH}\right), 7.15(\mathrm{~d}, \mathrm{~J}=8.4$ $\mathrm{Hz}, 1 \mathrm{H}, 1-\mathrm{CH}) ;{ }^{13} \mathrm{C}$ NMR $75.5 \mathrm{MHz} \delta\left(\mathrm{CDCl}_{3}\right): 12.32$, 26.17, 27.31, 29.51, 32.60, 36.47, 37.50, 37.96, 43.19, 43.81, 47.14, 48.10, 81.92, 112.65, 115.20, 126.49, 132.49, 138.15, 153.30; LRMS calculated for $\mathrm{C}_{19} \mathrm{H}_{25}{ }^{79} \mathrm{BrO}_{2}: 364.5$, found $365.0[\mathrm{M}+\mathrm{H}]^{+}$.

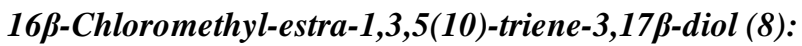

White solid; IR $v$ (film): $3380(\mathrm{OH}) ;{ }^{1} \mathrm{H}$ NMR $400 \mathrm{MHz}$ $\delta\left(\mathrm{CDCl}_{3}\right): 0.84\left(\mathrm{~s}, 3 \mathrm{H}, 18-\mathrm{CH}_{3}\right), 1.15-2.40$ (residual protons from the steroid), $2.60(\mathrm{~m}, 1 \mathrm{H}, 16 \alpha-\mathrm{CH}), 2.85(\mathrm{~m}, 2 \mathrm{H}, 6-$ $\left.\mathrm{CH}_{2}\right), 3.54\left(\mathrm{dd}, \mathrm{J}_{1}=8.3 \mathrm{~Hz}\right.$ and $\mathrm{J}_{2}=10.7 \mathrm{~Hz}, 1 \mathrm{H}$ of $\left.\mathrm{CH}_{2} \mathrm{Cl}\right)$, $3.88\left(\mathrm{dd}, \mathrm{J}_{1}=6.8 \mathrm{~Hz}\right.$ and $\mathrm{J}_{2}=10.8 \mathrm{~Hz}, 1 \mathrm{H}$ of $\left.\mathrm{CH}_{2} \mathrm{Cl}\right), 3.91$ $(\mathrm{d}, \mathrm{J}=10.8 \mathrm{~Hz}, 1 \mathrm{H}, 17 \alpha-\mathrm{CH}), 6.59(\mathrm{~d}, \mathrm{~J}=2.4 \mathrm{~Hz}, 1 \mathrm{H}, 4-$ $\mathrm{CH}), 6.65\left(\mathrm{dd}, \mathrm{J}_{1}=8.4 \mathrm{~Hz}, \mathrm{~J}_{2}=2.4 \mathrm{~Hz}, 1 \mathrm{H}, 2-\mathrm{CH}\right), 7.17(\mathrm{~d}, \mathrm{~J}$ $=8.4 \mathrm{~Hz}, 1 \mathrm{H}, 1-\mathrm{CH}) ;{ }^{13} \mathrm{C}$ NMR $75.5 \mathrm{MHz} \delta\left(\mathrm{CDCl}_{3}\right): 12.24$, 26.20, 27.33, 29.52, 31.18, 37.49, 37.97, 43.03, 44.28, 47.14, 48.36, 62.51, 81.73, 112.65, 115.20, 126.49, 135.58, 138.15, 153.30; LRMS calculated for $\mathrm{C}_{19} \mathrm{H}_{25} \mathrm{ClO}_{2}: 320.5$, found 365.1 for $\mathrm{C}_{20} \mathrm{H}_{26} \mathrm{ClO}_{4}\left[\mathrm{M}+\mathrm{COOH}^{-}\right]$.

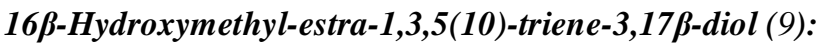

White solid; ${ }^{1} \mathrm{H}$ NMR $400 \mathrm{MHz} \delta\left(\mathrm{CD}_{3} \mathrm{OD}\right): 0.82$ (s, 3H, 18- $\mathrm{CH}_{3}$ ), 1.10-2.50 (residual protons from the steroid), 2.78 $\left(\mathrm{m}, 2 \mathrm{H}, 6-\mathrm{CH}_{2}\right), 3.54\left(\mathrm{dd}, \mathrm{J}_{1}=10.8 \mathrm{~Hz}\right.$ and $\mathrm{J}_{2}=7.6 \mathrm{~Hz}, 1 \mathrm{H}$ of $\left.\mathrm{CH}_{2} \mathrm{OH}\right), 3.84\left(\mathrm{~m}, 1 \mathrm{H}\right.$ of $\left.\mathrm{CH}_{2} \mathrm{OH}\right), 3.85(\mathrm{~d}, \mathrm{~J}=10.0 \mathrm{~Hz}, 17 \alpha-$ $\mathrm{CH}), 6.49(\mathrm{~d}, \mathrm{~J}=2.5 \mathrm{~Hz}, 1 \mathrm{H}, 4-\mathrm{CH}), 6.55\left(\mathrm{dd}, \mathrm{J}_{1}=8.4 \mathrm{~Hz}\right.$ and $\left.\mathrm{J}_{2}=2.5 \mathrm{~Hz}, 1 \mathrm{H}, 2-\mathrm{CH}\right), 7.09\left(\mathrm{~d}, \mathrm{~J}_{1}=8.4 \mathrm{~Hz}, 1 \mathrm{H}, 1-\mathrm{CH}\right)$; ${ }^{13} \mathrm{C}$ NMR $75.5 \mathrm{MHz} \delta\left(\mathrm{CD}_{3} \mathrm{OD}\right): 12.92,27.62,28.76,30.26$, $30.73,38.85,39.94,43.36,45.30,45.36,50.21,65.55,83.39$, 113.70, 116.00, 127.20, 132.55, 138.76, 155.91; LRMS calculated for $\mathrm{C}_{19} \mathrm{H}_{26} \mathrm{O}_{3}: 302.3$, found $301.3[\mathrm{M}-\mathrm{H}]^{-}$.

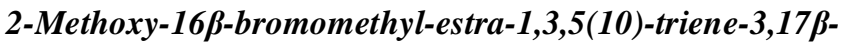 $\operatorname{diol}(10)$ :}

White solid; IR v (film): $3505(\mathrm{OH}) ;{ }^{1} \mathrm{H}$ NMR $400 \mathrm{MHz}$ $\delta\left(\mathrm{CDCl}_{3}\right): 0.84$ (s, $\left.3 \mathrm{H}, 18-\mathrm{CH}_{3}\right), 1.10-2.40$ (residual protons from the steroid), $2.70(\mathrm{~m}, 1 \mathrm{H}, 16 \alpha-\mathrm{CH}), 2.79(\mathrm{~m}, 2 \mathrm{H}, 6-$ $\left.\mathrm{CH}_{2}\right), 3.38\left(\mathrm{t}, \mathrm{J}=9.5 \mathrm{~Hz}, 1 \mathrm{H}\right.$ of $\left.\mathrm{CH}_{2} \mathrm{Br}\right), 3.77\left(\mathrm{dd}, \mathrm{J}_{1}=6.6 \mathrm{~Hz}\right.$ and $\mathrm{J}_{2}=9.8 \mathrm{~Hz}, 1 \mathrm{H}$ of $\left.\mathrm{CH}_{2} \mathrm{Br}\right), 3.88\left(\mathrm{~s}, 3 \mathrm{H}, \mathrm{OCH}_{3}\right), 3.89(\mathrm{~d}$, $\mathrm{J}=7.8 \mathrm{~Hz}, 1 \mathrm{H}, 17 \alpha-\mathrm{CH}), 6.67(\mathrm{~s}, 1 \mathrm{H}, 4-\mathrm{CH}), 6.81(\mathrm{~s}, 1 \mathrm{H}, 1-$ $\mathrm{CH}) ;{ }^{13} \mathrm{C}$ NMR $75.5 \mathrm{MHz} \delta\left(\mathrm{CDCl}_{3}\right): 12.33,26.47,27.45$, $28.88,32.58,36.44,37.56,37.96,43.22$, 44.15, 44.43, 48.10, $56.00,81.88,107.94,114.58,129.38,131.50,143.44$, 144.53; LRMS calculated for $\mathrm{C}_{20} \mathrm{H}_{26}{ }^{79} \mathrm{BrO}_{3}$ : 394.4 , found $395.0[\mathrm{M}+\mathrm{H}]^{+}$.

\section{2-Methoxy-16/-hydroxymethyl-estra-1,3,5(10)-triene- 3,17ß-diol (11):}

White solid; IR $v$ (film) $\mathrm{cm}^{-1}: 3380(\mathrm{OH}) ;{ }^{1} \mathrm{H}$ NMR 400 $\mathrm{MHz} \delta\left(\mathrm{CDCl}_{3}\right): 0.87\left(\mathrm{~s}, 3 \mathrm{H}, 18-\mathrm{CH}_{3}\right), 1.00-2.30$ (residual protons from the steroid), $2.50(\mathrm{~m}, 1 \mathrm{H}, 16 \alpha-\mathrm{CH}), 2.79(\mathrm{~m}$, $\left.2 \mathrm{H}, 6-\mathrm{CH}_{2}\right), 3.69\left(\mathrm{dd}, \mathrm{J}_{1}=4.3 \mathrm{~Hz}\right.$ and $\mathrm{J}_{2}=10.0 \mathrm{~Hz}, 1 \mathrm{H}$ of $\left.\mathrm{CH}_{2} \mathrm{OH}\right), 3.87\left(\mathrm{~m}, 1 \mathrm{H}\right.$ of $\left.\mathrm{CH}_{2} \mathrm{OH}\right), 3.88\left(\mathrm{~s}, 3 \mathrm{H}, \mathrm{OCH}_{3}\right), 3.99$ $(\mathrm{d}, \mathrm{J}=9.8 \mathrm{~Hz}, 1 \mathrm{H}, 17 \alpha-\mathrm{CH}), 6.67(\mathrm{~s}, 1 \mathrm{H}, 4-\mathrm{CH}), 6.81(\mathrm{~s}, 1 \mathrm{H}$, $1-\mathrm{CH}) ;{ }^{13} \mathrm{C}$ NMR $75.5 \mathrm{MHz} \delta\left(\mathrm{CDCl}_{3}\right): 12.27,26.56,27.54$, $27.79,28.94,37.68,38.09,41.97,44.12,44.27,49.03,56.03$, $64.74,83.06,107.98,114.58,129.43,131.61,143.46$, 144.56; LRMS calculated for $\mathrm{C}_{20} \mathrm{H}_{28} \mathrm{O}_{4}$ : 332.6 , found 331.2 $[\mathrm{M}-\mathrm{H}]^{\circ}$.

\section{Synthesis of 2-methoxy-3-tert-butyldimethylsilyloxy-16 $\alpha$ -} allyl-estra-1,3,5(10)-trien-17ß-ol (23):

A solution of diisopropylamine $(0.199 \mathrm{~mL}, 1.42 \mathrm{mmol})$ in dry THF $(20 \mathrm{~mL})$ was stirred under argon at $0{ }^{\circ} \mathrm{C}$ and a solution of $n$-butyllithium in hexanes $(0.57 \mathrm{~mL}, 1.42 \mathrm{mmol})$ was added dropwise. After 45 minutes, the resulting lithium diisopropylamide (LDA) solution was cooled at $-78{ }^{\circ} \mathrm{C}$ and $14(0.535 \mathrm{~g}, 1.29 \mathrm{mmol})$ dissolved in dry THF $(10 \mathrm{~mL})$ was added dropwise. The mixture was allowed to stir for 1 hour at $0{ }^{\circ} \mathrm{C}$, then cooled again to $-78{ }^{\circ} \mathrm{C}$ and allyl bromide $(0.123$ $\mathrm{mL}, 1.42 \mathrm{mmol}$ ) was added dropwise. The reaction mixture was stirred overnight from $-78{ }^{\circ} \mathrm{C}$ to room temperature. Water was added to quench the reaction and the crude product was extracted with EtOAc. The organic phase was washed 
with a saturated $\mathrm{NaCl}$ aqueous solution, dried over $\mathrm{Na}_{2} \mathrm{SO}_{4}$ and evaporated under reduced pressure. A solution of $\mathrm{LiAlH}_{4}$ in THF (1.65 mL, $1.65 \mathrm{mmol}$ ) was added dropwise to a solution of crude $\alpha / \beta$-allyl derivative $22(0.535 \mathrm{~g}, 1.18 \mathrm{mmol})$ dissolved in dry THF $(15 \mathrm{~mL})$ and cooled at $0{ }^{\circ} \mathrm{C}$. The reaction was completed after 30 minutes. Water was slowly added at $0{ }^{\circ} \mathrm{C}$ to quench the reaction and the crude product was extracted using EtOAc. The organic phase was washed with a saturated $\mathrm{NaCl}$ aqueous solution, dried over $\mathrm{Na}_{2} \mathrm{SO}_{4}$, then filtered and evaporated under reduced pressure. The crude product was purified by flash chromatography, using a mixture of hexanes and EtOAc (9/1) as eluent to give $\mathbf{2 3}$ in $66 \%$ yield for two steps (14 to $\mathbf{2 3}$ ). Only the 16 $\alpha$-isomer was recovered. White solid; IR $v$ (film): $3380(\mathrm{OH}) ;{ }^{1} \mathrm{H}$ NMR $300 \mathrm{MHz} \delta\left(\mathrm{CDCl}_{3}\right): 0.14$ (s, $\left.6 \mathrm{H}, \mathrm{Si}\left(\mathrm{CH}_{3}\right)_{2}\right), 0.82$ (s, $3 \mathrm{H}, 18-\mathrm{CH}_{3}$ ), 0.98 (s, 9H, $t$-Bu of TBDMS), 1.20-2.40 (residual protons from the steroid), $2.72\left(\mathrm{~m}, 2 \mathrm{H}, 6-\mathrm{CH}_{2}\right), 3.32$ $(\mathrm{d}, \mathrm{J}=7.5 \mathrm{~Hz}, 1 \mathrm{H}, 17 \alpha-\mathrm{CH}), 3.76\left(\mathrm{~s}, 3 \mathrm{H}, 2-\mathrm{CH}_{3} \mathrm{O}\right), 5.03(\mathrm{~d}$, $\mathrm{J}=10.5 \mathrm{~Hz}, 1 \mathrm{H}$ of $\left.\mathrm{CH}=\mathrm{CH}_{2}\right), 5.09(\mathrm{~d}, \mathrm{~J}=17.4 \mathrm{~Hz}, 1 \mathrm{H}$ of $\left.\mathrm{CH}=\mathrm{CH}_{2}\right), 5.88\left(\mathrm{~m}, 1 \mathrm{H}, \mathrm{CH}=\mathrm{CH}_{2}\right), 6.54(\mathrm{~s}, 1 \mathrm{H}, 1-\mathrm{CH}), 6.76$ (s, $1 \mathrm{H}, 4-\mathrm{CH}) ;{ }^{13} \mathrm{C}$ NMR $75.5 \mathrm{MHz} \delta\left(\mathrm{CDCl}_{3}\right):-4.60(2 \mathrm{X})$, $11.92,18.41,25.74$ (3X), 26.30, 27.34, 28.79, 29.69, 36.81, $38.40,39.62,43.31,44.07,44.30,48.32,55.82,87.39$, $109.79,115.72,120.95,128.93,133.11,137.84,142.82$, 148.61 .

Synthesis of 2-methoxy-3-tert-butyldimethylsilyloxy-16a(3'-hydroxypropyl)-estra-1,3,5(10)-trien-17ß-ol (24):

To a stirred solution of $23(0.287 \mathrm{~g}, 0.629 \mathrm{mmol})$ in dry THF $(20 \mathrm{~mL})$ at $0{ }^{\circ} \mathrm{C}$ a solution of borane in THF $(2.83 \mathrm{~mL}$, $2.83 \mathrm{mmol}$ ) was added dropwise. The mixture was allowed to react under argon for 3 hours, then a solution of $30 \%$ (w/v) $\mathrm{H}_{2} \mathrm{O}_{2}(286 \mu \mathrm{L})$ and $\mathrm{NaOAc}(257 \mathrm{mg})$ in water $(780$ $\mu \mathrm{L})$ was added. The resulting mixture was stirred at room temperature for 1 hour. The reaction was quenched by addition of water and extracted with EtOAc. The organic phase was washed with a saturated $\mathrm{NaCl}$ aqueous solution, dried over $\mathrm{Na}_{2} \mathrm{SO}_{4}$, then filtered and evaporated under reduced pressure. The crude product was purified by flash chromatography using a mixture of hexanes and EtOAc (7/3) as eluent to give 24 in $66 \%$ yield. ${ }^{1} \mathrm{H}$ NMR $400 \mathrm{MHz} \delta$ $\left(\mathrm{CDCl}_{3}\right): 0.17$ (s, 6H, $\left.\mathrm{Si}\left(\mathrm{CH}_{3}\right)_{2}\right), 0.84$ (s, 3H, 18- $\left.\mathrm{CH}_{3}\right), 1.01$ ( $\mathrm{s}, 9 \mathrm{H}, t$-Bu of TBDMS), 1.20-2.40 (residual protons from the steroid), $2.74\left(\mathrm{~m}, 2 \mathrm{H}, 6-\mathrm{CH}_{2}\right), 3.33(\mathrm{~d}, \mathrm{~J}=7.4 \mathrm{~Hz}, 1 \mathrm{H}$, $17 \alpha-\mathrm{CH}), 3.72\left(\mathrm{~m}, 2 \mathrm{H}, 3^{\prime}-\mathrm{CH}_{2} \mathrm{OH}\right), 3.79\left(\mathrm{~s}, 3 \mathrm{H}, 2-\mathrm{CH}_{3} \mathrm{O}\right)$, $6.56(\mathrm{~s}, 1 \mathrm{H}, 4-\mathrm{CH}), 6.79(\mathrm{~s}, 1 \mathrm{H}, 1-\mathrm{CH}) ;{ }^{13} \mathrm{C}$ NMR $75.5 \mathrm{MHz}$ $\delta\left(\mathrm{CDCl}_{3}\right):-4.58(2 \mathrm{X}), 12.01,18.43,25.77(3 \mathrm{X}), 26.33$, 27.36, 28.82, 30.37, 31.24, 32.20, 36.85, 38.45, 43.37, 44.22, $44.31,48.35,55.85,63.28,88.01,109.82,120.99,128.95$, $133.11,142.70,148.65$.

\section{Synthesis of 2-methoxy-3-tert-butyldimethylsilyloxy-16a-} (3'-bromopropyl)-estra-1,3,5(10)-trien-17ß-ol (25):

A solution of $24(0.095 \mathrm{~g}, 0.200 \mathrm{mmol}), \mathrm{PPh}_{3}(0.105 \mathrm{~g}$, $0.400 \mathrm{mmol})$ and $\mathrm{CBr}_{4}(0.133 \mathrm{~g}, 0.400 \mathrm{mmol})$ in dry $\mathrm{CH}_{2} \mathrm{Cl}_{2}$ $(10 \mathrm{~mL})$ was stirred at $0{ }^{\circ} \mathrm{C}$ under argon. The reaction was monitored by TLC and was completed after 3 hours. The crude mixture was pre-adsorbed on silica gel and purified by flash chromatography using hexanes and EtOAc (95/5) as eluent to give 25 in $64 \%$ yield. White solid; ${ }^{1} \mathrm{H}$ NMR 400
$\mathrm{MHz} \delta\left(\mathrm{CDCl}_{3}\right): 0.17\left(\mathrm{~s}, 6 \mathrm{H}, \mathrm{Si}\left(\mathrm{CH}_{3}\right)_{2}\right), 0.84$ (s, 3H, 18$\mathrm{CH}_{3}$ ), 1.01 (s, 9H, $t$-Bu of TBDMS), 1.20-2.35 (residual protons from the steroid), $2.74\left(\mathrm{~m}, 2 \mathrm{H}, 6-\mathrm{CH}_{2}\right), 3.31(\mathrm{~d}, \mathrm{~J}=7.2$ $\mathrm{Hz}, 1 \mathrm{H}, 17 \alpha-\mathrm{CH}), 3.47\left(\mathrm{t}, \mathrm{J}=6.3 \mathrm{~Hz}, 1.33 \mathrm{H}, 3^{\prime}-\mathrm{CH}_{2} \mathrm{Br}\right.$ ), $3.60\left(\mathrm{t}, \mathrm{J}=6.3 \mathrm{~Hz}, 0.67 \mathrm{H}, 3^{\prime}-\mathrm{CH}_{2} \mathrm{Br}\right), 3.79\left(\mathrm{~s}, 3 \mathrm{H}, 2-\mathrm{CH}_{3} \mathrm{O}\right)$, $6.57(\mathrm{~s}, 1 \mathrm{H}, 4-\mathrm{CH}), 6.78(\mathrm{~s}, 1 \mathrm{H}, 1-\mathrm{CH})$.

\section{Synthesis of 2-methoxy-16a-(3'-bromopropyl)-estra-1,3,5} (10)-triene-3,17ß-diol (12):

The silylether $\mathbf{2 5}$ was dissolved in a methanolic solution of $\mathrm{HCl}(2 \%, \mathrm{v} / \mathrm{v})$ and the resulting mixture was stirred at room temperature for 3 hours. Water was added, the $\mathrm{MeOH}$ evaporated under reduced pressure and the residue extracted with EtOAc. The organic phase was washed with a saturated $\mathrm{NaCl}$ aqueous solution and dried over $\mathrm{Na}_{2} \mathrm{SO}_{4}$. After evaporation under reduced pressure, the crude product was purified by flash chromatography, using a mixture of hexanes and EtOAc (8/2) as eluent to give $\mathbf{1 2}$ in $\mathbf{7 5} \%$ yield. White solid; ${ }^{1} \mathrm{H}$ NMR $400 \mathrm{MHz} \delta\left(\mathrm{CDCl}_{3}\right): 0.83\left(\mathrm{~s}, 3 \mathrm{H}, 18-\mathrm{CH}_{3}\right), 1.25-$ 2.30 (residual protons from the steroid), $2.78(\mathrm{~m}, 2 \mathrm{H}, 6-$ $\left.\mathrm{CH}_{2}\right), 3.32(\mathrm{~d}, \mathrm{~J}=7.3 \mathrm{~Hz}, 1 \mathrm{H}, 17 \alpha-\mathrm{CH}), 3.47(\mathrm{t}, \mathrm{J}=6.7 \mathrm{~Hz}$, $2 \mathrm{H}, 3$ ' $-\mathrm{CH}_{2} \mathrm{Br}$ ), 3.88 (s, 3H, 2- $\mathrm{CH}_{3} \mathrm{O}$ ), 5.50 (broad, $1 \mathrm{H}, \mathrm{OH}$ ), $6.67(\mathrm{~s}, 1 \mathrm{H}, 4-\mathrm{CH}), 6.81(\mathrm{~s}, 1 \mathrm{H}, 1-\mathrm{CH}) ;{ }^{13} \mathrm{C} \mathrm{NMR} 75.5 \mathrm{MHz}$ $\delta\left(\mathrm{CDCl}_{3}\right): 11.87,26.43,27.23,28.91,30.06,31.62,34.21$, $36.71,38.49,43.10,44.12$, 44.21, 45.34, 48.29, 56.00, 87.98, 107.95, 114.56, 129.44, 131.62, 143.40, 144.52; LRMS calculated for $\mathrm{C}_{22} \mathrm{H}_{31}{ }^{79} \mathrm{BrO}_{3}$ : 422.5, found $423.1[\mathrm{M}+\mathrm{H}]^{+}$and $405.2\left[\mathrm{M}-\mathrm{H}_{2} \mathrm{O}\right]^{+}$.

\section{In Vitro Assay for the Inhibition of 17ß-HSD1}

The enzymatic assay was performed as previously described [22]. Briefly, Human Embryonic Kidney (HEK)-293 cells transfected with cDNA encoding for $17 \beta$-HSD1 were sonicated to liberate the crude enzyme that was used as the enzymatic pool without further purification. The enzymatic assay was performed as follows: a stock solution was first prepared containing the radiolabeled substrate $\left[{ }^{14} \mathrm{C}\right]$-E1 $(0.1$ $\mu \mathrm{M}), \mathrm{NADH}(1 \mathrm{mM})$ in a phosphate buffer $(\mathrm{pH} 7.4,50 \mathrm{mM}$ $\mathrm{KH}_{2} \mathrm{PO}_{4}$, EDTA $1 \mathrm{mM}, 20 \%$ glycerol). For the assay, 890 $\mu \mathrm{L}$ of the stock solution and $10 \mu \mathrm{L}$ of a solution of inhibitor dissolved in ethanol were added in a tube. The reaction was started by adding $100 \mu \mathrm{L}$ of a solution of crude enzyme prepared as described above. The mixture was incubated for 1 hour at $37^{\circ} \mathrm{C}$, and the reaction was stopped by adding an excess of unlabeled E1 and E2. Steroids were extracted with diethyl ether and solvent was removed under reduced pressure. The residue was dissolved in $\mathrm{CH}_{2} \mathrm{Cl}_{2}$, spotted on a silica gel plate (TLC, $20 \mathrm{~cm} \times 20 \mathrm{~cm} \times 0.2 \mathrm{~mm}$, Kieselgel 60 F254) and eluted with $\mathrm{CH}_{2} \mathrm{Cl}_{2}$ /EtOAc (9:1). Less polar $\mathrm{E}_{1}$ and more polar $\mathrm{E}_{2}$ were identified on TLC as two rows of visible spots under UV light. Radioactivity signals associated to $\left[{ }^{14} \mathrm{C}\right]-\mathrm{E} 1$ and $\left[{ }^{14} \mathrm{C}\right]-\mathrm{E} 2$ were detected and quantified using a Storm 860 Imager (Molecular Dynamics, Sunny Vale, CA, USA). The percentage of transformation of $\left[{ }^{14} \mathrm{C}\right]-\mathrm{E} 1$ into $\left[{ }^{14} \mathrm{C}\right]-\mathrm{E} 2$ was calculated as follows: $\%$ trans. $=100 \mathrm{X}\left[{ }^{14} \mathrm{C}\right]-$ E2 (unit) / $\left(\left[{ }^{14} \mathrm{C}\right]-\mathrm{E} 1\right.$ (unit) $+\left[{ }^{14} \mathrm{C}\right]-\mathrm{E} 2$ (unit)). From the curve of the $\%$ trans. versus the concentration of inhibitor, the $\mathrm{IC}_{50}$ value was calculated using an unweighted iterative leastsqares method for four-parameter logistic curve fitting $\left(\mathrm{DE}_{50}\right.$ program, CHUL Research Center, Québec QC, Canada). 


\section{In Vitro Assay for the Determination of Estrogenic Activity}

The ER-positive breast cancer cell line T-47D was obtained from the American Type Culture Collection (ATCC) and maintained in $75 \mathrm{~cm}^{2}$ culture flasks at $37^{\circ} \mathrm{C}$ under $5 \%$ $\mathrm{CO}_{2}$ humidified atmosphere in RPMI medium (SigmaAldrich, Oakville, ON, Canada) supplemented with $10 \%$ foetal bovine serum (FBS), L-glutamine $(2 \mathrm{mM})$, penicillin $(100 \mathrm{IU} / \mathrm{mL})$, streptomycin $(100 \mu \mathrm{g} / \mathrm{mL})$ and estradiol (1 $\mathrm{nM}$ ). For the cell growth assay, T-47D cells were resuspended in RPMI medium (without E2) supplemented with insulin $(50 \mathrm{ng} / \mathrm{mL})$ and $5 \%$ dextran-coated charcoal treated FBS to remove the remaining estrogen present in the serum. Aliquots $(100 \mu \mathrm{L})$ of the cell suspension were seeded in 96 -well plates (3000 cells/well). After 48 hours, the medium was changed with appropriate dilution of the different inhibitors and reference compounds in medium and was re- placed every 2 days until 8 days of treatment. Quantification of cell growth was determined using CellTitter $96^{\circledR} A Q_{\text {ueous }}$ Solution Cell Proliferation Assay (Promega, Nepean, ON, Canada) following the manufacturer's instructions. To determine the proliferative (estrogenic) activity, the cells were grown in absence (control fixed as $100 \%$ ) or presence of the tested compound at indicated concentrations.

\section{In Vivo Assay for the Determination of Estrogenic Activity}

The in vivo estrogenic activity of two compounds was measured by stimulation of uterine and vagina weight in adult ovariectomized (OVX) Balb/c mice (body wt $-18-20$ g) sacrificed 10 days after ovariectomy (day 0 ). Compounds 5a and 12 (at doses of 10 and $50 \mu \mathrm{g} /$ mouse), estrone (0.06 $\mu \mathrm{g} /$ mouse $)$ and estradiol $(0.02 \mu \mathrm{g})$ dissolved in ethanol were injected s.c. in each appropriate group of mice in a solution

Estrone $(\mathrm{R}=\mathrm{H})$ or

2-Methoxy-estrone $\left(\mathrm{R}=\mathrm{OCH}_{3}\right)$

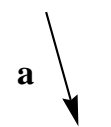

TBDMSO<smiles>[R]c1cc2c(cc1[Se])CCC1C2CC[C@]2(C)C(=O)CCC12</smiles>

$13(\mathrm{R}=\mathrm{H})$

$14\left(\mathrm{R}=\mathrm{OCH}_{3}\right)$

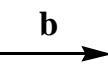

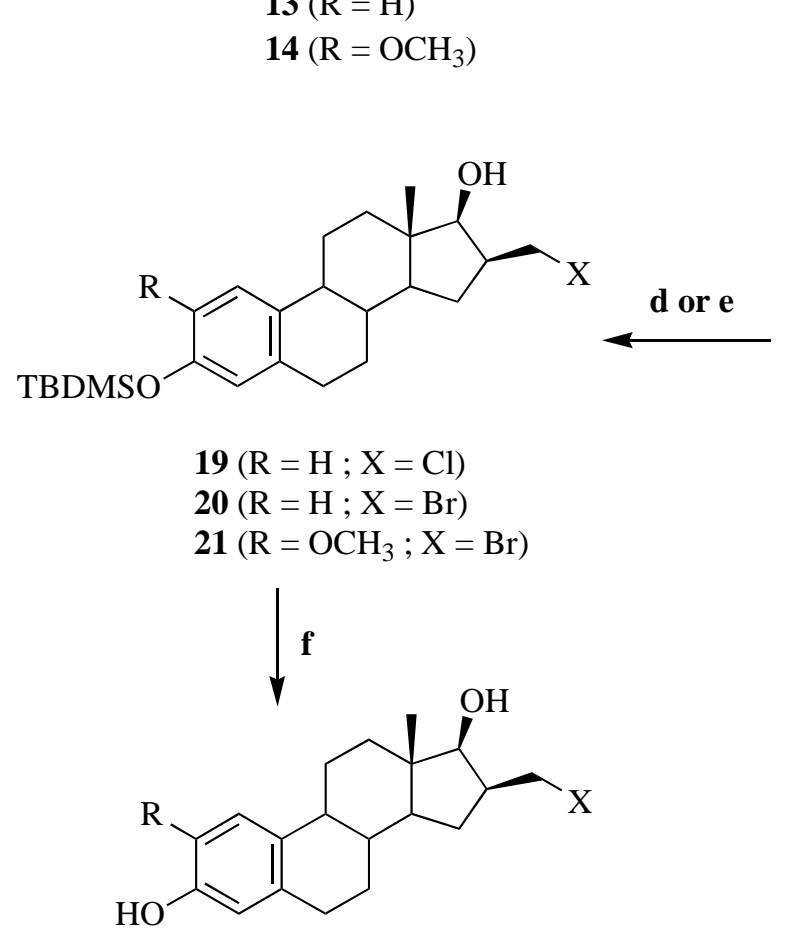

$7(\mathrm{R}=\mathrm{H} ; \mathrm{X}=\mathrm{Br})$

$8(\mathrm{R}=\mathrm{H} ; \mathrm{X}=\mathrm{Cl})$

$10\left(\mathrm{R}=\mathrm{OCH}_{3} ; \mathrm{X}=\mathrm{Br}\right)$<smiles>[R]c1cc2c(cc1OC)CCC1C2CC[C@]2(C)C(=O)C(C(=O)OC)CC12</smiles>

$15(\mathrm{R}=\mathrm{H})$

$16\left(\mathrm{R}=\mathrm{OCH}_{3}\right)$<smiles>[R]c1cc2c(cc1OS(C)(=O)=O)CCC1C2CC[C@@]2(C)[C@H]1C[C@@H](CO)[C@H]2O</smiles>

$17(\mathrm{R}=\mathrm{H})$

$18\left(\mathrm{R}=\mathrm{OCH}_{3}\right)$

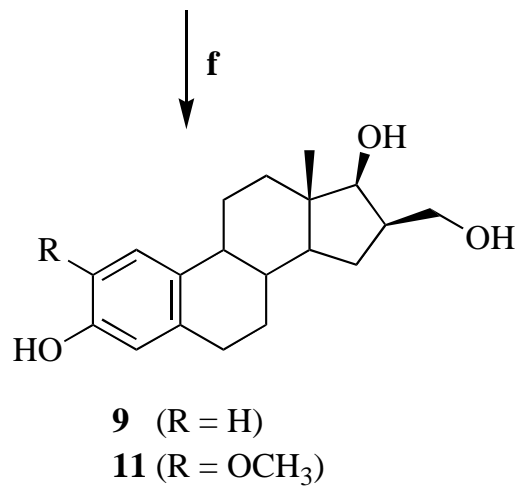

Fig. (2). Synthesis of 7-11. The reagents are: (a) TBDMS-Cl, imidazole; (b) LDA, methylcyanoformate, $\mathrm{HMPA}$ (c) $\mathrm{LiAlH}_{4}$; (d) $\mathrm{Ph}_{3} \mathrm{P}, \mathrm{CCl}_{4}$; (e) $\mathrm{Ph}_{3} \mathrm{P}, \mathrm{CBr}_{4}$; (f) $2 \% \mathrm{HCl}$ in $\mathrm{MeOH}$. 
of $0.4 \%$ methylcellulose ( $8 \%$ ethanol final concentration) for a total volume of $0.2 \mathrm{~mL}$, twice daily for 9 days, starting on day 2 of the protocol for a total of 18 injections. Vehicle only was injected to intact and CTR-OVX groups. After sacrifice, the uteri and vagina were rapidly removed, freed from fat and connective tissue and weighed. Results are the means \pm SEM of 8 mice per group.

\section{RESULTS AND DISCUSSION}

\section{Chemical Synthesis}

The sequences of reactions needed to obtain compounds 7-12 are represented in Fig. (2) and (3). Following a similar route already employed by us [18], 17 and 18 were synthesized without difficulty starting from E1 and 2-MeO-E1. First, this involves the protection of the phenol group with a tert-butyldimethylsilyl (TBDMS) ether followed by the alkylation using methylcyanoformate to afford after a silica gel chromatography, mostly the more stable $\beta$-epimer (compounds 15 and 16). Then, a classical reduction with lithium aluminium hydride of both ketone and ester groups gave us, after purification with silica gel, the desired $16 \beta$ hydroxymethyl compounds $\mathbf{1 7}$ and $\mathbf{1 8}$. We then used either $\mathrm{CBr}_{4}$ or $\mathrm{CCl}_{4}$ with triphenylphosphine to obtain according to the case, the 16 16 -bromomethyl and 16 16 -chloromethyl derivatives 19-21. Another point should be mentioned about the chlorination or bromination of the primary alcohols $\mathbf{1 7}$ and 18 (conditions (d) and (e) of Fig. 2). If the reaction goes on for more than 4 hours, TBDMS hydrolysis occurs with a total removing of the TBDMS protective group after 12 hours. Despite this, the final compounds were easily obtained in expected good yields for these kinds of reactions. The TBDMS hydrolysis of compounds 17-21 was performed using a mild acidic condition $(2 \% \mathrm{HCl}$ in $\mathrm{MeOH})$ to afford compounds 7-11 in good yields.

The synthesis of $16 \alpha$-(3'-bromopropyl)-2-MeO-E2 (12) follows the route previously developed for inhibitor 5a [18], and the achievement of the synthesis did not encounter big issues (Fig. 3). However, after introduction of the allyl moiety upon the starting material 14, the isolation of the pure $16 \alpha$ isomer is not possible at this stage. The best way to do it is to perform the carbonyl reduction upon the crude mixture of $16 \alpha$ and $16 \beta$-allyl isomers 22 into corresponding alcohols. The isolation of the $16 \alpha$ isomer 23 becomes much more feasible by classical flash chromatography of isomeric alcohols instead of isomeric ketones 22.<smiles>COc1cc2c(cc1OC(C)(C)C)C1CC[C@]3(C)C(=O)CCC3C1CC2</smiles>

14<smiles>C=CC[C@H]1CC2C3CCc4cc(OC(C)(C)C)c(OC)cc4C3CC[C@]2(C)C1=O</smiles>

22

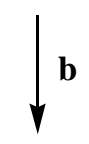<smiles>CCCCCCCO</smiles><smiles>C=C(/C=C(\C)OS(=O)(=O)[18O])CCC</smiles>

24

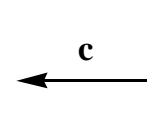<smiles>C=CC[C@H]1CC2C3CCc4cc(OS(C)(=O)=O)c(OC)cc4C3CC[C@]2(C)[C@@H]1O</smiles>

23<smiles>COc1cc2c(cc1OS(C)(=O)=O)CCC1C2CC[C@]2(C)C1CC[C@H]2O</smiles>

25<smiles>COc1cc2c(cc1O)CCC1C2CC[C@]2(C)C1C[C@H](C[13CH3])[C@@H]2O</smiles>

12

Fig. (3). Synthesis of 12. The reagents are: (a) LDA, allyl bromide; (b) $\mathrm{LiAlH}_{4} ;$ (c) $1 . \mathrm{CH}_{3}, 2 . \mathrm{H}_{2} \mathrm{O}_{2}, \mathrm{NaOAc}$ (d) $\mathrm{Ph}_{3} \mathrm{P}, \mathrm{CBr}$; (e) $2 \% \mathrm{HCl}$ in $\mathrm{MeOH}$. 
The 16ß-stereochemistry of final compounds 7-11 and the $16 \alpha$-stereochemistry of compound 12 were unambiguously confirmed by ${ }^{1} \mathrm{H}$ and ${ }^{13} \mathrm{C}$ NMR analysis. Indeed, we previously reported that proton and carbon signals at position 17 are useful probes for $\mathrm{C}-16$ and $\mathrm{C}-17$ stereochemistry determination [23]. All expected NMR probes were found in NMR spectra of final compounds (Table 2).

\section{In Vitro Study (17ß-HSD1 Inhibitory Activity)}

The $\mathrm{IC}_{50}$ values of synthesized compounds 7-12 and reference compounds 5a and E2 were determined in homogenate of HEK-293 cells overexpressing 17 $\beta$-HSD1 (Table 3). The enzyme preparation was incubated with $100 \mathrm{nM}$ of $\left[{ }^{14} \mathrm{C}\right]-\mathrm{E} 1$ in presence of the inhibitor at five different concentrations $(0.01,0.1,1.0,10$ and $30 \mu \mathrm{M})$ to obtain a good approximation of the $\mathrm{IC}_{50}$ value.

In the first protocol (assay A) we evaluated the inhibitory character of the E2 derivatives at all concentrations mentioned above. We can see that the inhibitor 5a, already synthesized by our research team [18], has good inhibitory effect upon $17 \beta$-HSD1 with $\mathrm{IC}_{50}$ values of $1.30 \mu \mathrm{M}$. In comparison, the non radioactive natural substrate E2, without a substituent at position 16 , weakly inhibited the enzyme $\left(\mathrm{IC}_{50}\right.$ $=7.34 \mu \mathrm{M})$. In the series of $16 \beta$-methylene derivatives of E2 (compounds 7-9), we can conclude that 7 (16 $\beta$-bromomethyl-E2) and 9 (16 $\beta$-hydroxymethyl-E2), with $\mathrm{IC}_{50}$ values of 1.20 and $1.49 \mu \mathrm{M}$, have comparable inhibitory effects than reference inhibitor 5a upon 17 $\beta$-HSD1. Compound 8 is not as good an inhibitor of $17 \beta$-HSD1 as the previous two with $\mathrm{IC}_{50}$ values over $3 \mu \mathrm{M}$. The $2-\mathrm{MeO}-\mathrm{E}_{2}$ derivatives 1012 were next tested in a second protocol (assay B). First, we can see that the $\mathrm{IC}_{50}$ values of $\mathbf{5} \mathbf{a}$ and $\mathbf{9}$ are consistent in both assays indicating that the results of the enzyme assays are reproducible (Table 3 ). The $\mathrm{IC}_{50}$ values of compounds 10-12 (5.91, 3.80 and $5.80 \mu \mathrm{M}$, respectively) are not as good as previously expected and the presence of a $2-\mathrm{MeO}$ group clearly decreases the inhibitory potency on $17 \beta$-HSD1. This negative effect of the 2-MeO group was recently observed in other families of 17 $\beta$-HSD1 inhibitors [24-26].

\section{In Vitro Study (Estrogenic Activity in $\mathrm{ER}^{+}$Cell Line)}

The breast cancer T-47D cell line was used to determine the estrogenic profile of inhibitors 7-12 (Fig. 4). These cells express the estrogen receptor (ER) and proliferate in pres-

Table 2. NMR Probes for 16 $\beta$ - and 16 $\alpha$-Derivatives of $17 \beta$-E2

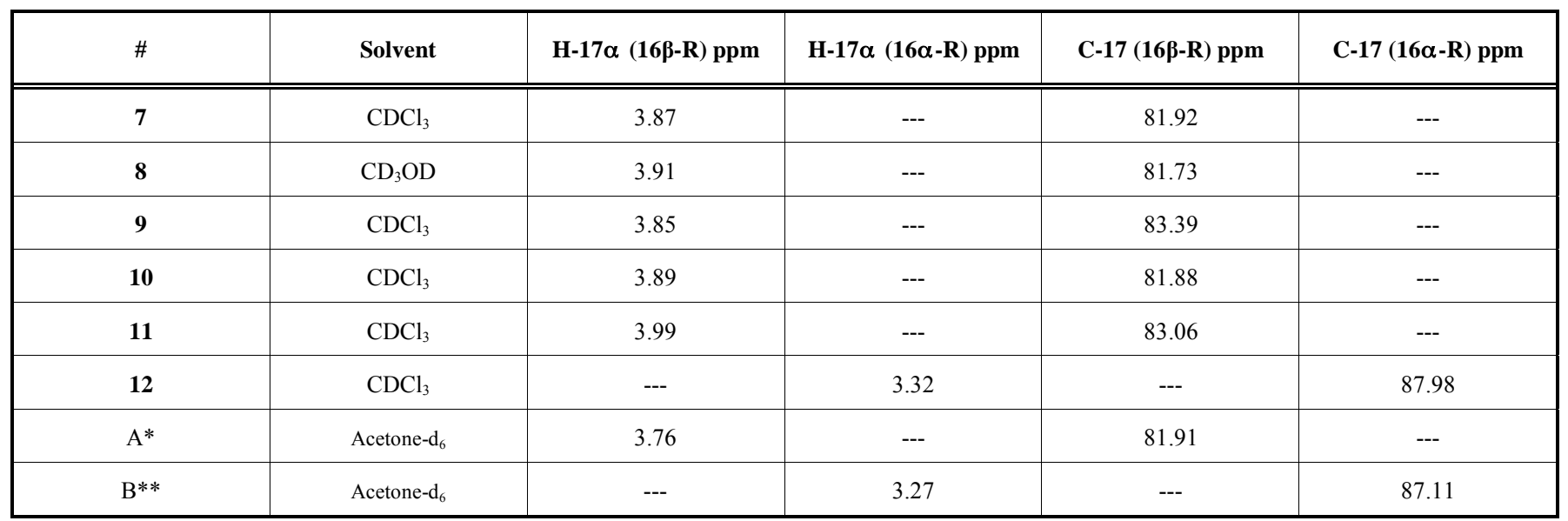

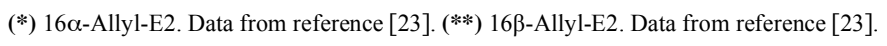

Table 3. Inhibition of 17 $\beta$-HSD1 Transformation of $\left[{ }^{14} \mathrm{C}\right]-\mathrm{E} 1$ into $\left[{ }^{14} \mathrm{C}\right]-\mathrm{E} 2$ by E2, 5a and 7-12

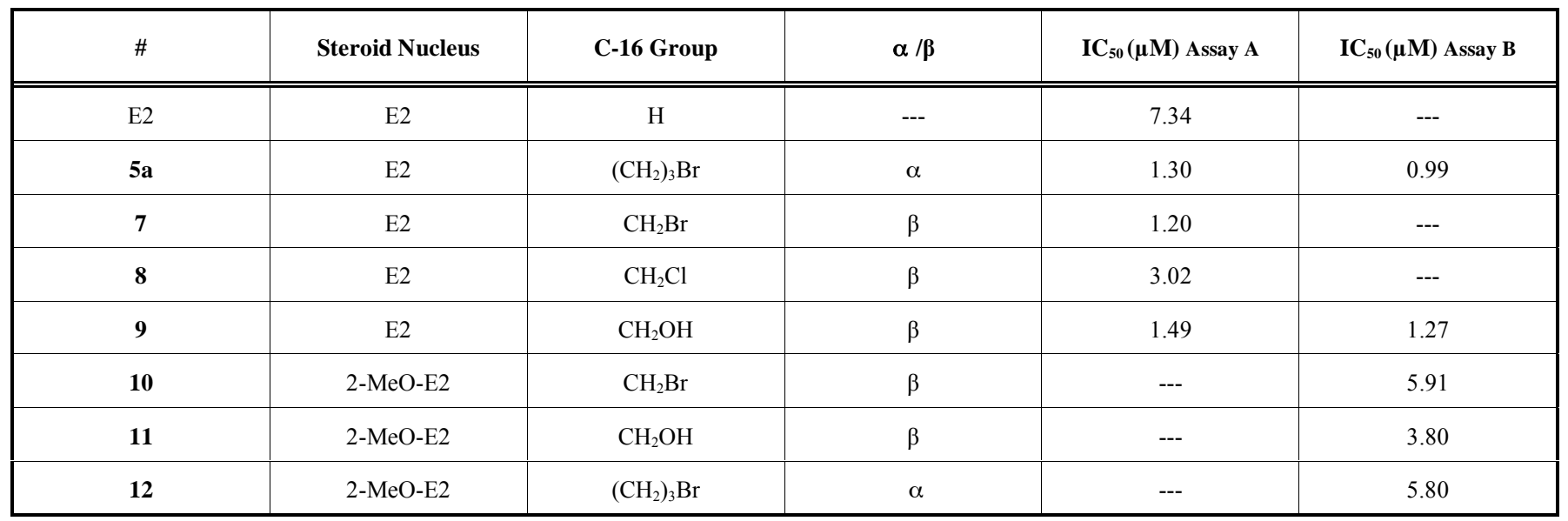


ence of estrogens. Similarly as observed for E2, the E2 derivatives 5a, 7, 8 and 9 clearly stimulated the cell growth. The 2-MeO-E2 derivatives 10-12 differently affected the cell growth. Thus, compound $\mathbf{1 0}$ is not estrogenic at $0.1 \mu \mathrm{M}$ but estrogenic at $1 \mu \mathrm{M}$, compound $\mathbf{1 1}$ does not induce proliferation at both concentrations, whereas $\mathbf{1 2}$ appears to be estrogenic. This last result is very deceptive considering the presence of a 2-MeO-E2 nucleus. To better understand the role of this nucleus on estrogenicity, the effect of 2-MeO-E2 derivative $\mathbf{1 2}$ and the E2 derivative 5a on T-47D cell proliferation was measured at several concentrations and compared with the 2-MeO-E2 nucleus only (without the 16 $\alpha$-side chain) Fig. (5). All three compounds induced the cell proliferation in the following order: $\mathbf{5 a}>\mathbf{1 2}>2$-MeO-E2. In fact, they produce an estrogenic effect over $0.01 \mu \mathrm{M}$ and have the same pattern of activity until $0.5 \mu \mathrm{M}$. Over $0.5 \mu \mathrm{M}$, cell growth decreased markedly in the presence of 2-MeO-E2 but not with $\mathbf{1 2}$ and 5a. For $\mathbf{1 2}$ and $\mathbf{5 a}$, cell growth increased until $3 \mu \mathrm{M}$ and $5 \mu \mathrm{M}$, respectively, and then started to decrease. These results illustrate that the 2-MeO-E2 derivatives are not estrogenic at a low concentration $(<0.01 \mu \mathrm{M})$ but are estrogenic in a range of concentrations, which vary according to the substituent added on the nucleus. At high concentrations, however, the effect on cell growth is reversed suggesting a non ER-dependent mechanism. In fact, we

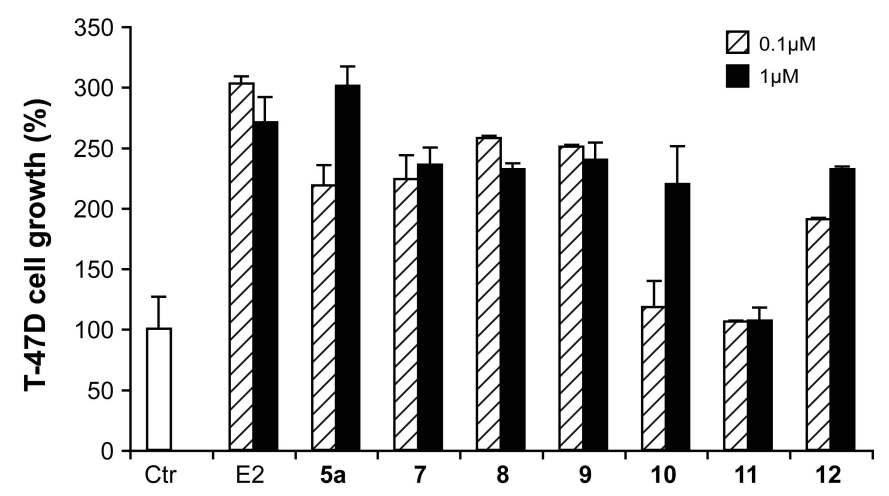

Fig. (4). Effect of E2, 5a and 7-12 on the proliferation of estrogensensitive T-47D cells.

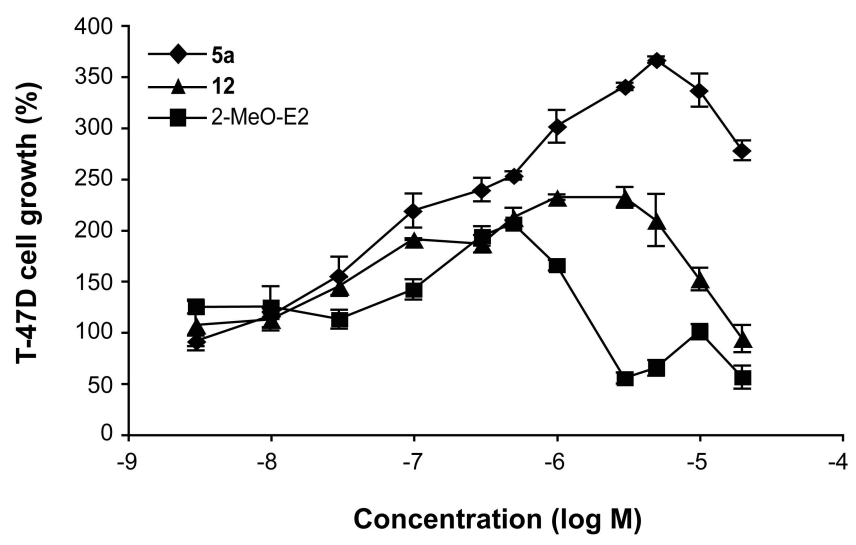

Fig. (5). Effect of 5a, 12 and 2-MeO-E2 on the proliferation of estrogensensitive T-47D cells.

observed cell death over $10 \mu \mathrm{M}$. Thus, the 2-MeO-E2 nucleus is less estrogenic than the E2 nucleus, however it kept a residual estrogenic character in T-47D cells before produc- ing a cytotoxic activity at higher concentrations. In estrogensensitive MCF-7 cells, La Vallee et al. [27] obtained a similar curve of proliferation with the 2-MeO-E2. Such results are in agreement with the conclusions of Sutherland et al. [28], which reported that 2-MeO-E2 produces both ERdependent and ER-independent effects. Moreover, it has been also reported that 2-MeO-E2 enhances inhibitory effects on tubulin polymerization and cancer cell growth, and inhibits the angiogenesis required for the growth of solid tumors [29-33].

\section{In Vivo Study (Estrogenic Activity in $\mathrm{ER}^{+}$Tissues)}

Estrogenic activity of tested compounds was investigated in vivo using the OVX mouse model by measuring the weight of the uterus (Fig. 6) and the vagina (Fig. 7), two estrogen-sensitive $\left(\mathrm{ER}^{+}\right)$tissues. As observed in Fig. (6), E1 and E2 increase the weight of the uterus. For the OVX mice control group, we have noticed a $66 \%$ reduction of the weight of the uterus compared with the group of mice intact; which is perfectly logical because this control group of mice has lowered the endogenous source of estrogens provided by the ovaries. When administrated s.c. to OVX mice, E1 (0.06 $\mu \mathrm{g}$ ) is converted into E2 by the 17ß-HSD1 and we observed an 7.5-time increase of the uterine weight compared to the control group (OVX-CTR). We also administered s.c. E2 $(0.02 \mu \mathrm{g})$ to the OVX mice with an 6.5-time increase of uterine weight compared to the control group (OVX-CTR). When we tested 5a, we could see that at a $10 \mu \mathrm{g}$ dose uterine growth is stimulated passing from $20 \mathrm{mg}$ for the OVX-CTR group to $100 \mathrm{mg}$ for the OVX-5a group. This result reflects the fact already observed by us that this inhibitor of $17 \beta-$ HSD1 stimulates the ER ${ }^{+}$cell line ZR-75-1 (data not shown) and MCF-7 (see above). In counterpart, at a $50 \mu \mathrm{g}$ injection dose, 5a weakly stimulates the growth of the uterus passing from $20 \mathrm{mg}$ for the OVX-CTR group to $39 \mathrm{mg}$ for the OVX5a group. One hypothesis to explain this unexpected result at the higher dose of $\mathbf{5 a}$ is that we have an ER-independent mechanism as discussed above, which is responsible for growth inhibition. In counterpart, at the low dose, we have an ER-dependent mechanism and cell stimulation by ER is favored.

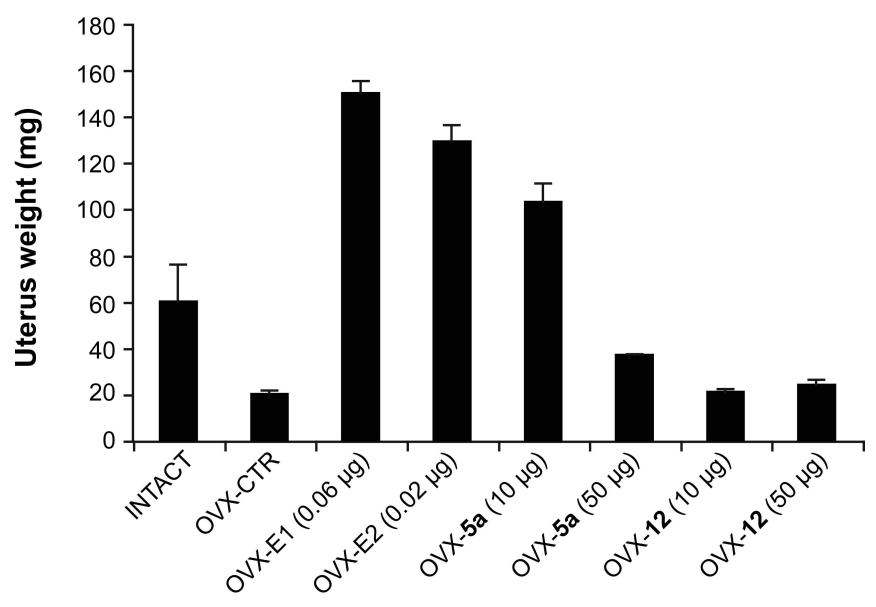

Fig. (6). Effect of E1, E2, 5a and $\mathbf{1 2}$ on the weight of estrogensensitive tissue (uterus) of ovariectomized Balb/c mice. CTR, control group (vehicle only); OVX, ovariectomized mice; E1, estrone; E2, estradiol. 


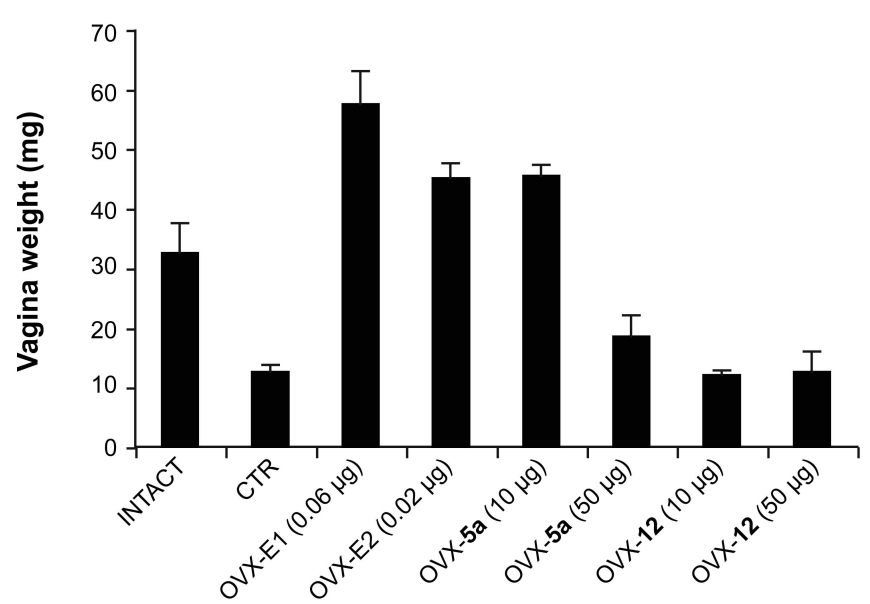

Fig. (7). Effect of E1, E2, 5a and $\mathbf{1 2}$ on the weight of estrogensensitive tissue (vagina) of ovariectomized Balb/c mice. CTR, control group (vehicle only); OVX, ovariectomized mice; E1, estrone; E2, estradiol.

Finally, when we tested the 2-MeO analogue of 5a, compound 12, at two doses of $10 \mu \mathrm{g}$ and $50 \mu \mathrm{g}$, we obtained no weight stimulation of the uterus reflecting the non-estrogenic character of $\mathbf{1 2}$ on the uterus at these two doses. Furthermore, the non-estrogenic character of $\mathbf{1 2}$ had been evaluated by measuring the weight of the vagina instead of the weight of the uterus (Fig. 7). Clearly, measuring of the vagina demonstrated the same tendency as previously observed with the uterus.

\section{CONCLUSIONS}

The 2-MeO-E2 nucleus was used as a strategy to reduce the estrogenicity of a series of inhibitors of $17 \beta-H S D 1$. The presence of the 2-MeO group clearly decreased the potency of these inhibitors in HEK-293 cells overexpressing 17 $\beta$ HSD1 and did not fully eliminate their proliferative estrogenic activity on T-47D $\mathrm{ER}^{+}$cells. However, no stimulation of estrogen-sensitive tissues (uterus and vagina) was observed with compound 12, when tested in vivo at two concentrations of 10 and $50 \mu \mathrm{g} /$ day. Although this last result is interesting, additional work will be needed to increase the inhibitory potency of compound $\mathbf{1 2}$ on $17 \beta$-HSD1 as well as to reduce its ER-binding affinity in order to obtain an inhibitor of $17 \beta-H S D 1$ acting in a range of concentrations without producing an estrogenic effect. On the other hand, this inhibitor could be alternatively used at high concentrations, thus providing an ER-independent cytotoxic effect on breast cancer cells and potential antiangiogenic effects. Considering the presence of the 2-MeO-E2 nucleus, it would be also interesting to perform other biological studies to measure the potential of compound $\mathbf{1 2}$ as angiogenesis inhibitor and its effectiveness upon the inhibition on tubulin polymerization.

\section{ACKNOWLEDGEMENTS}

We would like to thank the Canadian Institutes of Health Research (CIHR) for their financial support and the Fonds de la Recherche en Santé du Québec (FRSQ) for a Senior Fellowship (D.P.). We also thank Ms. Micheline Harvey for careful reading of the manuscript.

\section{REFERENCES}

[1] Moeller G, Adamski J. Multifunctionality of human 17 $\beta$-hydroxysteroid dehydrogenases. Mol Cell Endocrinol 2006; 248: 47-55.

[2] Lukacik P, Kavanagh KL, Oppermann U. Structure and function of human 17 $\beta$-hydroxysteroid dehydrogenases. Mol Cell Endocrinol 2006; 248: 61-71.

[3] Vihko P, Harkonen P, Soronen P, et al. 17 $\beta$-Hydroxysteroid dehydrogenases - their role in pathophysiology. Mol Cell Endocrinol 2004; 215: 83-8.

[4] Luu-The V. Analysis and characteristics of multiple types of human 17 $\beta$-hydroxysteroid dehydrogenase. J Steroid Biochem Mol Biol 2001; 76: 143-51.

[5] Labrie F, Luu-The V, Lin SX, et al. Intracrinology: Role of the family of 17 $\beta$-hydroxysteroid dehydrogenases in human physiology and disease. J Mol Endocrinol 2000; 25: 1-16.

[6] Moghrabi N, Andersson S. 17 $\beta$-Hydroxysteroid dehydrogenases: Physiological roles in health and disease. Trends Endocrinol Metab 1998; 9: 265-70.

[7] Gobec S, Brozic P, Rizner TL. Inhibitors of 17 $\beta$-hydroxysteroid dehydrogenase type 1 . Curr Med Chem 2008; 15: 137-50.

[8] Poirier D. Inhibitors of 17 $\beta$-hydroxysteroid dehydrogenases. Curr Med Chem 2003; 10: 453-77. and cited references.

[9] Smith HJ, Nicholls PJ, Simons C, Le Lain R. Inhibitors of steroidogenesis as agents for the treatment of hormone-dependent cancers. Expert Opin Ther Patents 2001; 11: 789-824.

[10] Poirier D, Bydal P, Tremblay MR, Sam KM, Luu-The V. Inhibitors of type II 17 $\beta$-hydroxysteroid dehydrogenase. Molec Cell Endocrinol 2001; 171: 119-28.

[11] Tremblay MR, Poirier D. Overview of a rational approach to design type I 17 $\beta$-hydroxysteroid dehydrogenase inhibitors without estrogenic activity: chemical synthesis and biological evaluation. J Steroid Biochem Mol Biol 1998; 66: 179-91.

[12] Penning TM. 17 $\beta$-Hydroxysteroid dehydrogenase: Inhibitors and inhibitor design. Endocr-Relat Cancer 1996; 3: 41-56.

[13] Luu-The V, Zhang Y, Poirier D, Labrie F. Characteristics of human types 1, 2 and 3 17 $\beta$-hydroxysteroid dehydrogenase activities: Oxidation/reduction and inhibition. J Steroid Biochem Mol Biol 1995; 55: 581-7.

[14] Ghosh D, Pletnev VZ, Zhu DW, et al. Structure of human estrogenic 17 $\beta$-hydroxysteroid dehydrogenase at $2.20 \AA$ resolution. Structure 1995; 3: 503-13.

[15] Azzi A, Rehse PH, Zhu DW, Campbell RL, Labrie F, Lin SX. Crystal structure of human estrogenic 17 $\beta$-hydroxysteroid dehydrogenase complexed with 17 $\beta$-estradiol. Nat Struct Biol 1996; 3: 665-8.

[16] Mazza C, Breton R, Housset D, Fontecilla-Camps JC. Unusual change stabilization of $\mathrm{NADP}^{+}$in $17 \beta$-hydroxysteroid dehydrogenase. J Biol Chem 1998; 273: 8145-52.

[17] Sawicki MW, Erman M, Puranen T, Vihko P, Ghosh D. Structure of the ternary complex of human $17 \beta$-hydroxysteroid dehydrogenase type 1 with 3-hydroxyestra-1,3,5,7-tetraen-17-one (equilin) and NADP ${ }^{+}$. Proc Natl Acad Sci USA 1999; 96: 840-5.

[18] Tremblay MR, Auger S, Poirier D. Synthesis of 16-(bromoalkyl)estradiols having inhibitory effect on human placental estradiol 17 $\beta$-hydroxysteroid dehydrogenase (17 $\beta$-HSD type 1). Bioorg Med Chem 1995; 3: 505-23.

[19] Merriam GR, MacLusky NJ, Picard MK, Naftolin F. Comparative properties of the catechol estrogens, I: methylation by catechol-Omethyltransferase and binding to cytosol estrogen receptors. Steroids 1980; 36: 1-11.

[20] Nambara T, Honma S, Akiyama S. Studies on steroid conjugates. III. New syntheses of 2-methoxyestrogens. Chem Pharm Bull 1970; 18: 474-80.

[21] Pelletier JD, Labrie F, Poirier D. N-butyl, N-methyl 11-[3', 17' $\beta$ (dihydroxy)-1',3',5'(10)'-estratrien-16' $\alpha$-yl]-9(R/S) bromoundecan amide: Synthesis and 17 $\beta$-HSD inhibiting, estrogenic and antiestrogenic activities. Steroids 1994; 59: 536-47.

[22] Tremblay MR, Lin SX, Poirier D. Chemical synthesis of $16 \beta$ propylaminoacyl derivatives of estradiol and their inhibitory potency on type 1 17 $\beta$-hydroxysteroid dehydrogenase and binding affinity on steroid receptors. Steroids 2001; 66: 821-31.

[23] Dionne P, Tchédam-Ngatcha B, Poirier D. D-ring allyl derivatives of $17 \beta$ - and $17 \alpha$-estradiols: Chemical synthesis and ${ }^{13} \mathrm{C}$ NMR data. Steroids 1997; 62: 674-81. 
[24] Laplante Y, Cadot C, Fournier MA, Poirier D. Estradiol and estrone $\mathrm{C}-16$ derivatives as inhibitors of type $117 \beta$-hydroxysteroid dehydrogenase: Blocking of $\mathrm{ER}^{+}$breast cancer cell proliferation induced by estrone. Bioorg Med Chem 2008; 16: 1849-60.

[25] Cadot C, Laplante Y, Kamal F, Luu-The V. Poirier D, C6-(N, Nbutyl-methyl-heptanamide) derivatives of estrone and estradiol as inhibitors of type $117 \beta$-hydroxysteroid dehydrogenase: Chemical synthesis and biological evaluation. Bioorg Med Chem 2007; 15: 714-26.

[26] Lawrence HR, Vicker N, Allan GM, et al. Novel and potent 17ßhydroxysteroid dehydrogenase type 1 inhibitors. J Med Chem 2005; 48: 2759-62.

[27] La Vallee TM, Zhan XH, Herbstritt CJ, Kough EC, Green SJ, Pribluda VS. 2-Methoxyestradiol inhibits proliferation and induces apoptosis independently of estrogen receptors $\alpha$ and $\beta$. Cancer Res 2002; 62: 3691-7.

[28] Sutherland TE, Schuliga M, Harris T, et al. 2-Methoxyestradiol is an estrogen receptor agonist that supports tumor growth in murine xenograft models of breast cancer. Clin Cancer Res 2005; 11: 1722-32.
[29] Cushman M, He HM, Katzenellenbogen JA, Varma RK. Hamel E, Lin CM. Synthesis of analogs of 2-methoxyestradiol with enhanced inhibitory effects on tubulin polymerisation and cancer cell growth. J Med Chem 1997; 40: 2323-34.

[30] Fotsis T, Zhang Y, Pepper MS, et al. The endogenous oestrogen metabolite 2-methoxyestradiol inhibits angiogenesis and suppresses tumour growth. Nature 1994; 368: 237-9.

[31] Klauber N, Parangi S, Flynn E, Hamel E, D'Amato RJ. Inhibition of angiogenesis and breast cancer in mice by the microtubule in hibitors 2-methoxyestradiol and taxol. Cancer Res 1997; 57: 81-6.

[32] Sutherland TE, Anderson RL, Hughes RA, et al. 2-Methoxyestradiol - a unique blend of activities generating a new class of antitumour/anti-inflammatory agents. Drug Discov Today 2007; 12: 577-84.

[33] Liu ZJ, Zhu BT. Concentration-dependent mitogenic and antiproliferative actions of 2-methoxyestradiol in estrogen receptorpositive human breast cancer cells. J Steroid Biochem Mol Biol 2004; 88: 265-75.

(c) Rouillard et al.; Licensee Bentham Open.

This is an open access article distributed under the terms of the Creative Commons Attribution License (http://creativecommons.org/licenses/by/2.5/), which permits unrestrictive use, distribution, and reproduction in any medium, provided the original work is properly cited. 